\title{
Effect of Amino Acids and Sodium Chloride on D-Sorbitol in Aqueous Solutions at Different Temperatures: Volumetric and Acoustic Approach
}

\section{Dorota Warmińska ${ }^{1}$ D}

Received: 26 January 2018 / Accepted: 14 July 2018 / Published online: 20 October 2018

(c) The Author(s) 2018

\begin{abstract}
Apparent molar volumes and apparent molar compressibilities for D-sorbitol in $(0.05$, $0.1,0.2$ and 0.3 ) $\mathrm{mol} \cdot \mathrm{kg}^{-1}$ aqueous solutions of L-alanine, L-cysteine and L-histidine and $\mathrm{NaCl}$ have been determined from measurements of solution density at $T=(288.15,298.15$, 308.15 and 318.15$) \mathrm{K}$ and sound velocity at $T=298.15 \mathrm{~K}$, as a function of the concentration of the sugar alcohol. The data were used to obtain the limiting apparent molar volumes, limiting apparent molar compressibilities and the corresponding transfer parameters. Limiting apparent molar expansibilities and their second order derivatives and volume interaction coefficients were also estimated. These parameters are discussed in terms of D-sorbitol and co-solute (amino acid or sodium chloride) interactions in aqueous solutions.
\end{abstract}

Keywords Density $\cdot$ Sound velocity $\cdot$ D-Sorbitol $\cdot$ Aqueous amino acid solutions $\cdot$ Sodium chloride

\section{Introduction}

In recent years, sugar alcohols, owing to their desirable properties, have found applications in many branches of industry. Properties of polyols, such as good taste, low calorie content and little effect on blood sugar levels have paved the way for the use of these compounds in the production of prepared foods, cosmetics and pharmaceuticals [1-3]. It has been established that polyols enable stabilization of the native state of proteins and affect their denaturalization, solubility and folding/unfolding behavior [4, 5]. Thus, knowledge of the properties of polyols in aqueous solutions of amino acids is essential for understanding the chemistry of biological systems.

Among various polyols, D-sorbitol, a six-carbon sugar alcohol, is widely used as sweetening agent, plasticizer, as well as capsule and tablet diluent [6, 7]. It is known that D-sorbitol, despite having a structure similar to that of its isomer D-mannitol, shows a real difference in solubility in water and in osmotic pressure coefficients [8]. It has also

Dorota Warmińska

dorwarmi@pg.edu.pl

1 Department of Physical Chemistry, Chemical Faculty, Gdańsk University of Technology, Narutowicza 11/12, 80-233 Gdańsk, Poland 
been suggested that D-sorbitol is a relatively stronger disruptor of the water structure than D-mannitol [9].

To the best of our knowledge, reports on the effects of amino acids on the structure of water modified by sugar alcohol are still scare. Most of the thermodynamic data have been collected for systems with D-mannitol and xylitol [10-15]. So far, few studies have focused on the volumetric and acoustic properties of aqueous solutions containing D-sorbitol and amino acids. Density and sound velocity data at $298.15 \mathrm{~K}$ for some ternary mixtures (amino acid + D-sorbitol + water) have been reported by Jha and Kishore [16]. Moreover, Ren et al. published volumetric data for such systems for a wider range of temperatures [17]. The authors of both publications calculated the limiting molar volumes of transfer from water to aqueous D-sorbitol solutions for amino acids and they postulated the existence of hydrophilic/polar group interactions in the systems. The same conclusion was reached by Banipal et al. who studied volumetric properties of D-sorbitol in aqueous solutions of L-glycine [18].

The present study was aimed at providing some additional data on the properties of D-sorbitol in aqueous amino acid solutions using volumetric and acoustic measurements. The densities at $T=(288.15,298.15,308.15$ and 318.15$) \mathrm{K}$ and sound velocities at $T=298.15 \mathrm{~K}$ for D-sorbitol in $(0.05,0.1,0.2$ and 0.3$) \mathrm{mol} \cdot \mathrm{kg}^{-1}$ aqueous solutions of L-alanine, L-cysteine and L-histidine are reported. Additionally, corresponding data for D-sorbitol in aqueous solutions of $\mathrm{NaCl}$ was also collected. The paper presents calculations of the apparent molar volumes and the apparent molar compressibilities, as well as their limiting values. The corresponding transfer parameters and limiting apparent molar expansibilities are also estimated. The evaluated parameters were correlated and interpreted in terms of the different types of interactions that can occur in ternary systems. The structure making/ breaking tendency of D-sorbitol in aqueous amino acid or $\mathrm{NaCl}$ solutions is also analyzed.

\section{Experimental}

\subsection{Chemical Used}

D-sorbitol ( $\geq 0.98)$, L-alanine $(\geq 0.99)$, L-cysteine $(\geq 0.99)$ and L-histidine $(\geq 0.99)$ were obtained from Carl Roth GMbH + Co. KG, sodium chloride $(\geq 0.999)$ was purchased from POCh and were used without further purification. Table 1 briefly describes the properties of the chemicals and Fig. 1 shows their structures. Before measurements, D-sorbitol and all amino acids and $\mathrm{NaCl}$ were dried under reduced pressure at $323 \mathrm{~K}$. Deionized, doubly

Table 1 Provenance and mass fraction purity of the compounds studied

\begin{tabular}{llll}
\hline Chemical name & Source & CAS number & Mass fraction purity \\
\hline D-Sorbitol & Carl Roth GMbH + Co. KG & $50-70-4$ & $\geq 0.98^{\mathrm{a}}$ \\
L-Alanine & Carl Roth GMbH + Co. KG & $56-41-7$ & $\geq 0.99^{\mathrm{a}}$ \\
L-Cysteine & Carl Roth GMbH + Co. KG & $52-90-4$ & $\geq 0.99^{\mathrm{a}}$ \\
L-Histidine & Carl Roth GMbH + Co. KG & $71-00-1$ & $\geq 0.99^{\mathrm{a}}$ \\
NaCl & POCh & $7647-14-5$ & $\geq 0.999^{\mathrm{a}}$ \\
\hline
\end{tabular}

${ }^{a}$ As stated by the supplier. The chemicals were used as such without further purification 
(a)

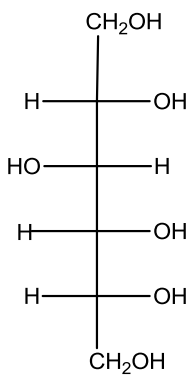

(b)

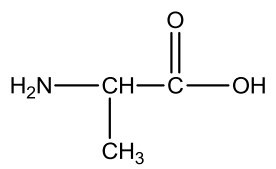

(c)

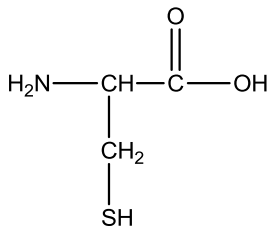

(d)

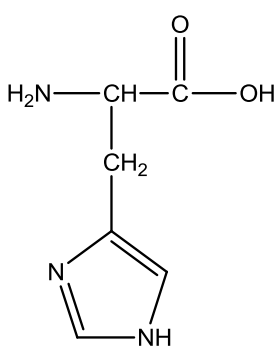

Fig. 1 Molecular structures of D-sorbitol (a), L-alanine (b), L-cysteine (c) and L-histidine (d)

distilled, degassed water with a specific conductance of $1.15 \times 10^{-6} \mathrm{~S} \cdot \mathrm{cm}^{-1}$ was used for the preparation of $(0.05,0.1,0.2$ and 0.3$) \mathrm{mol} \cdot \mathrm{kg}^{-1}$ solutions of L-alanine and L-cysteine, whereas in the case of L-histidine only three solutions $(0.05,0.1$ and 0.2$) \mathrm{mol} \cdot \mathrm{kg}^{-1}$ were made due to its lower solubility. All the solutions were prepared by weight dilution of the stock solution of D-sorbitol using a Mettler Toledo balance with a precision of $\pm 0.0001 \mathrm{~g}$.

\subsection{Apparatus and Procedure}

The densities of the ternary mixtures were measured at different temperatures using a digital vibrating-tube analyzer (Anton Paar DMA 5000, Austria), equipped with a built-in solid-state thermostat that controls the temperature by means of a combination of thermoelectric Peltier elements and an intergrated Pt-100 resistance thermometer with an accuracy of $0.01 \mathrm{~K}$. The measurement cell in the apparatus is made of borosilicate glass. Prior to each series of measurements, the apparatus was calibrated using doubly distilled and degassed water and with dry air at atmospheric pressure $(0.1 \mathrm{MPa})$. The standard uncertainty in the density measurements was within $\pm 35 \times 10^{-3} \mathrm{~kg} \cdot \mathrm{m}^{-3}$.

The sound velocities were determined with a standard uncertainty of $0.15 \mathrm{~m} \cdot \mathrm{s}^{-1}$ using the sound analyzer OPTIME 1.0 from OPTEL (Poland), based on the time of flight method. Measurements are based on the determination of the time that the acoustic signal with a frequency of $8 \mathrm{MHz}$ takes to pass through a sample of known length. The length of the quartz measurement cell was determined with doubly distilled water, with the value $1496.69 \mathrm{~m} \cdot \mathrm{s}^{-1}$ used as the sound velocity in pure water at $298.15 \mathrm{~K}$. Temperature during measurements was stabilized by a constant temperature bath (model: PolyScience 8202) at $298.15 \pm 0.01 \mathrm{~K}$.

\section{Results and Discussion}

\subsection{Volumetric Properties}

The experimental values of molality, density and apparent molar volume at various temperatures of the solutions of D-sorbitol in aqueous L-alanine, L-cysteine, L-histidine and $\mathrm{NaCl}$ are reported in Tables 2, 3, 4 and 5. The results show that density increases with an increase in the concentration of D-sorbitol and also with the molality of amino acids or sodium 


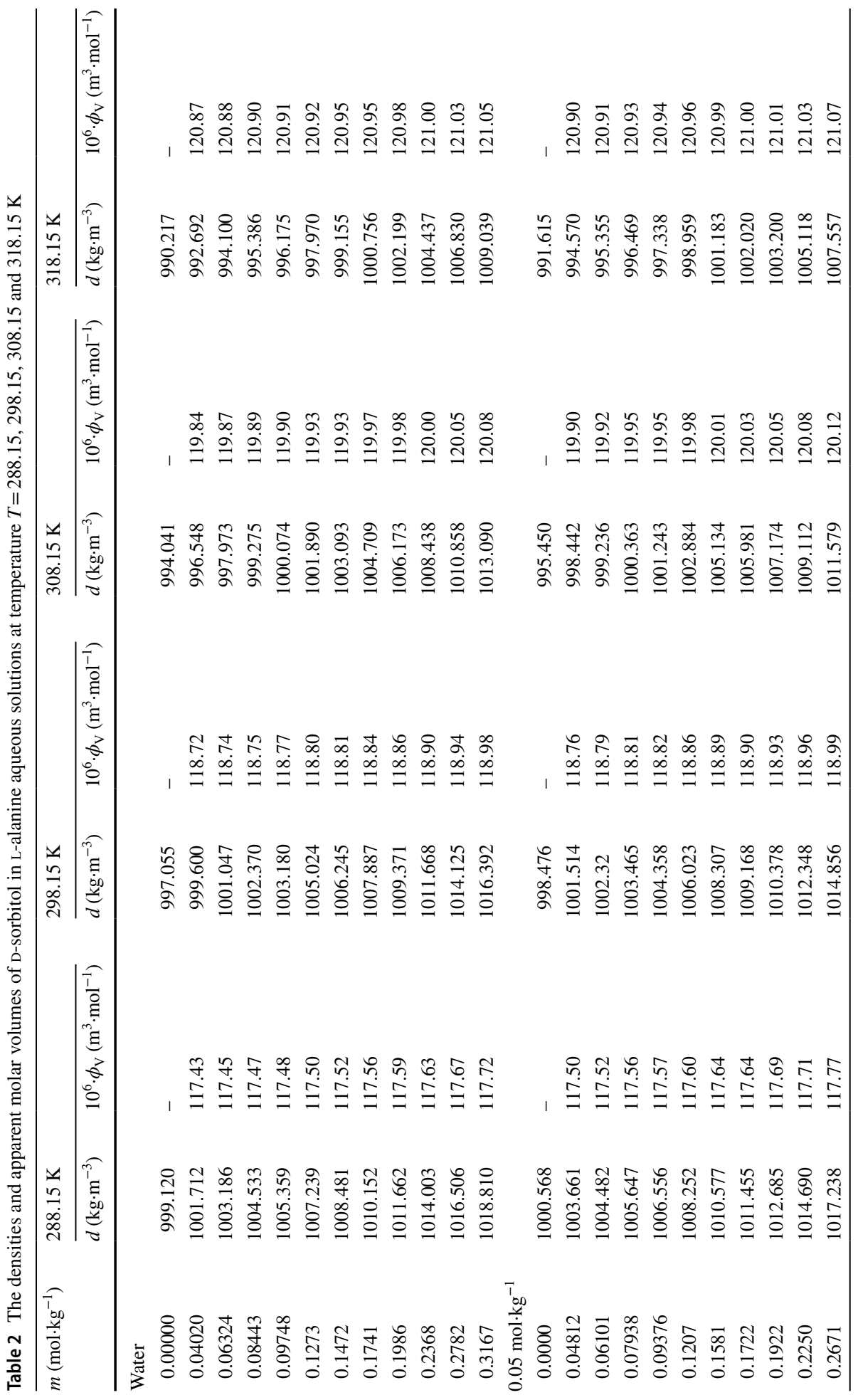




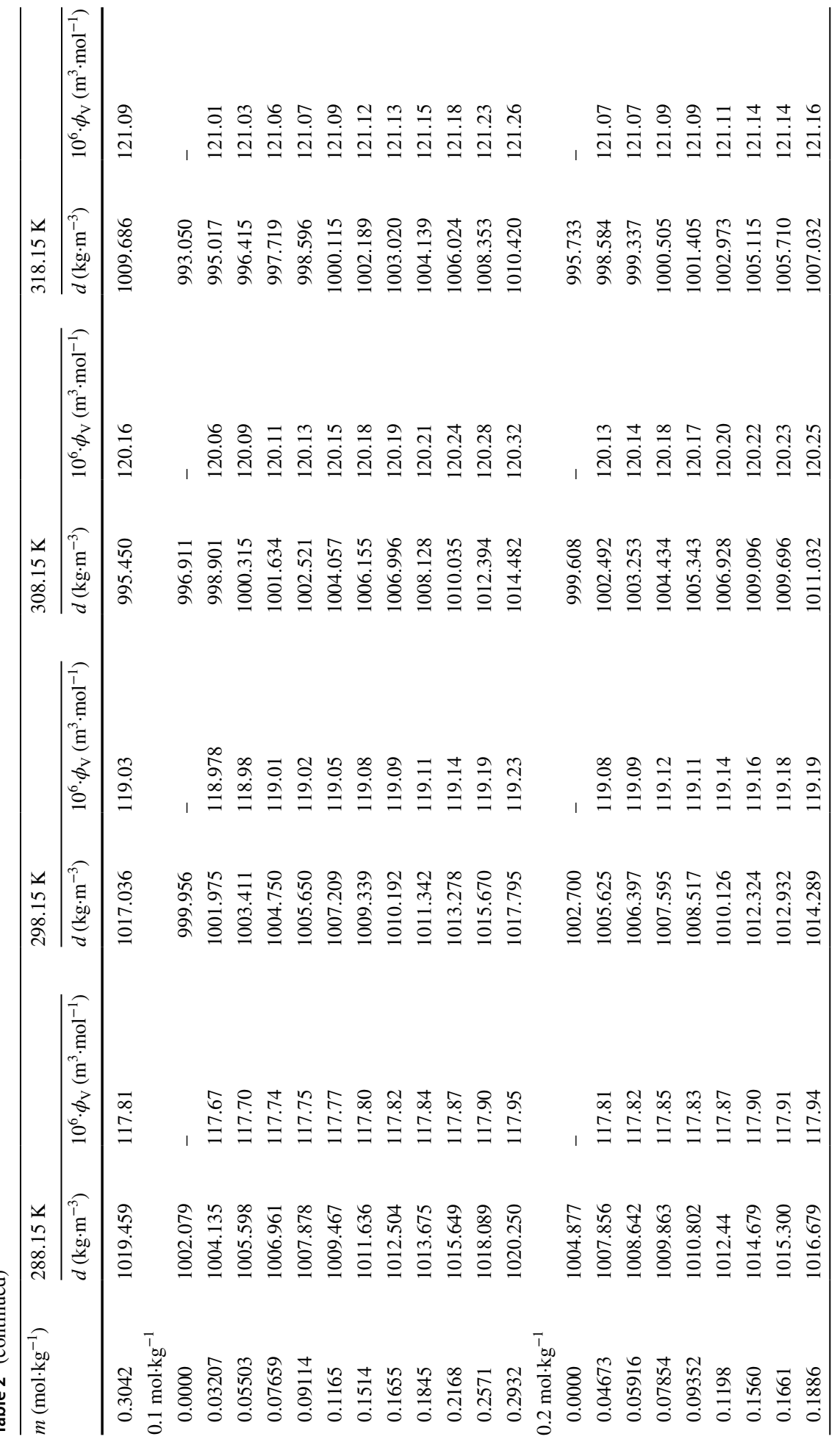




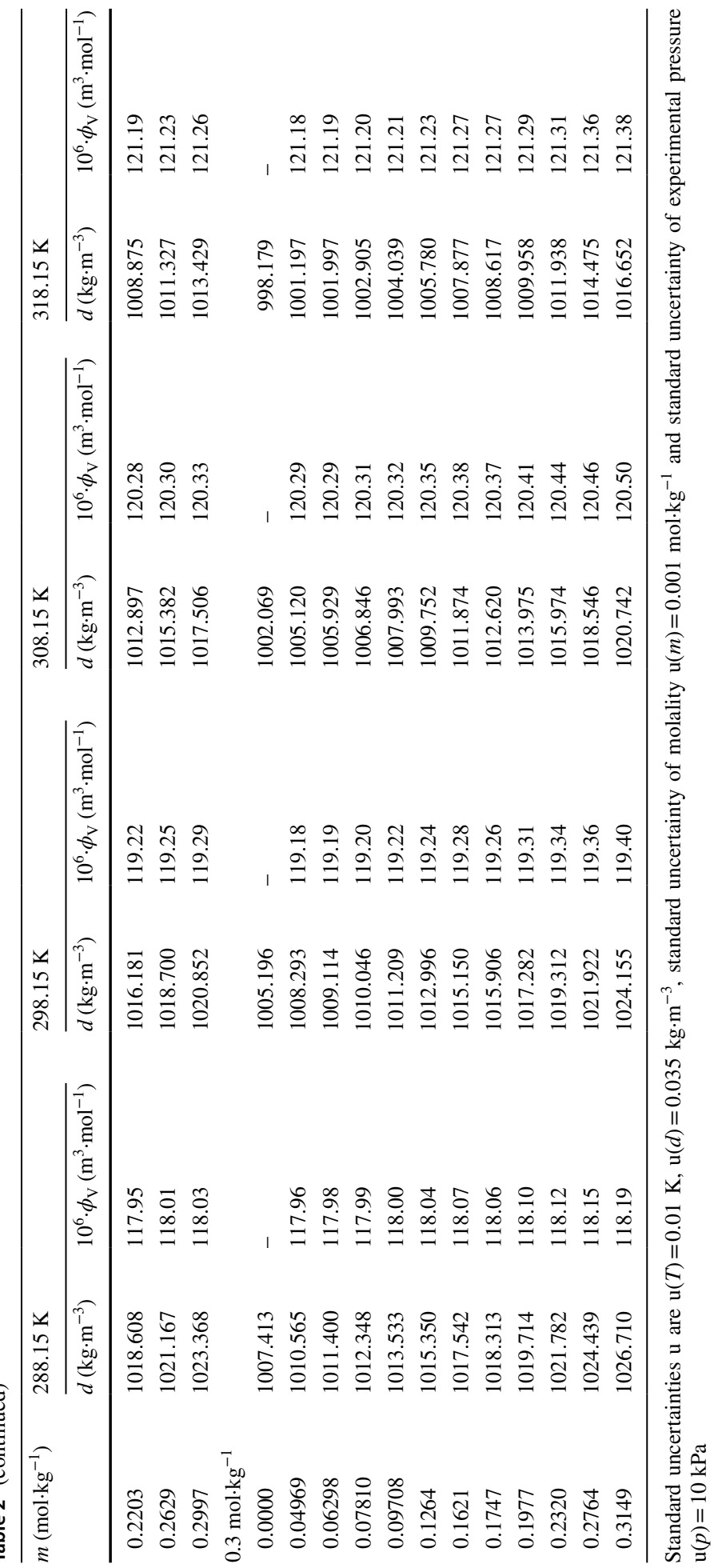




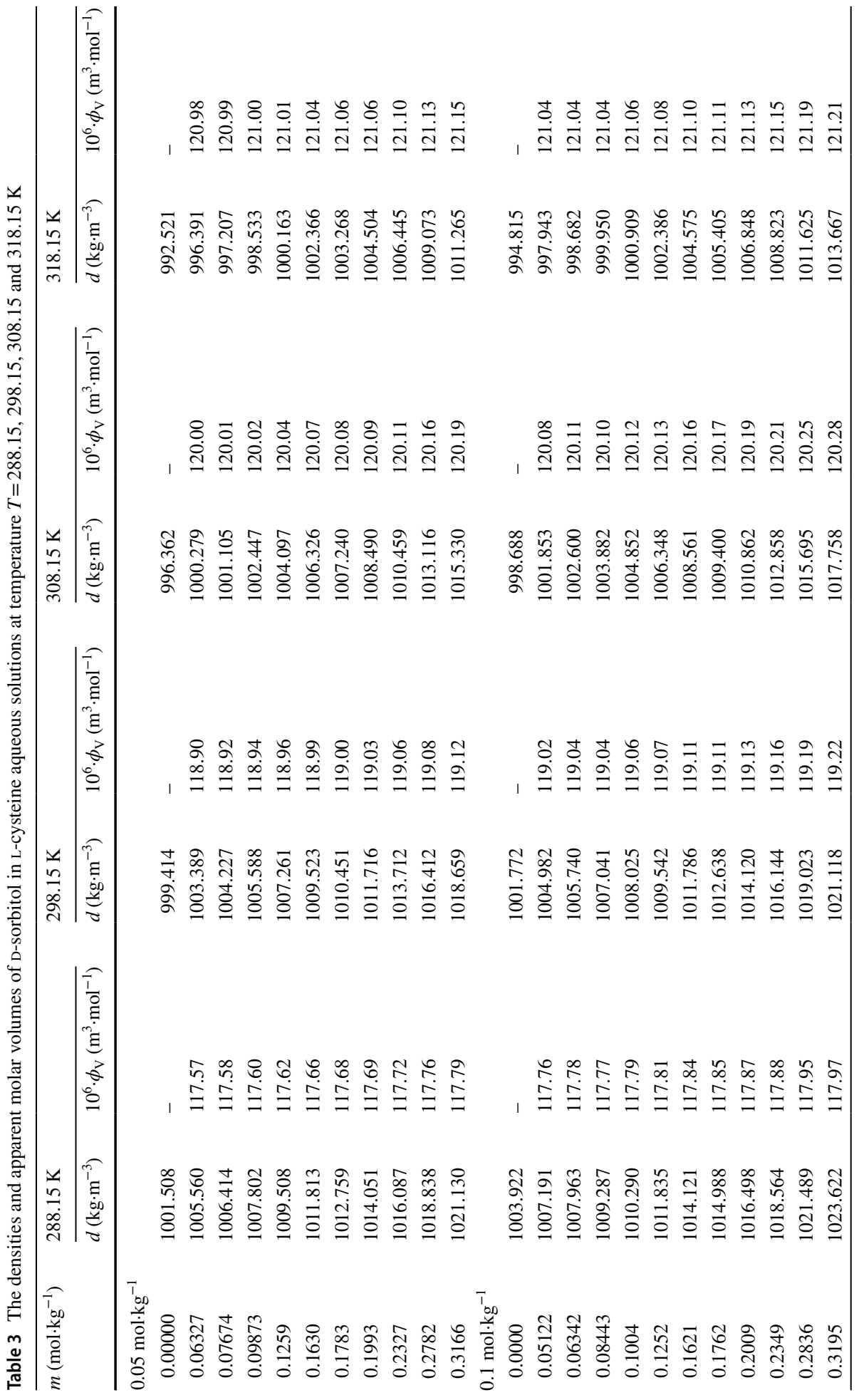




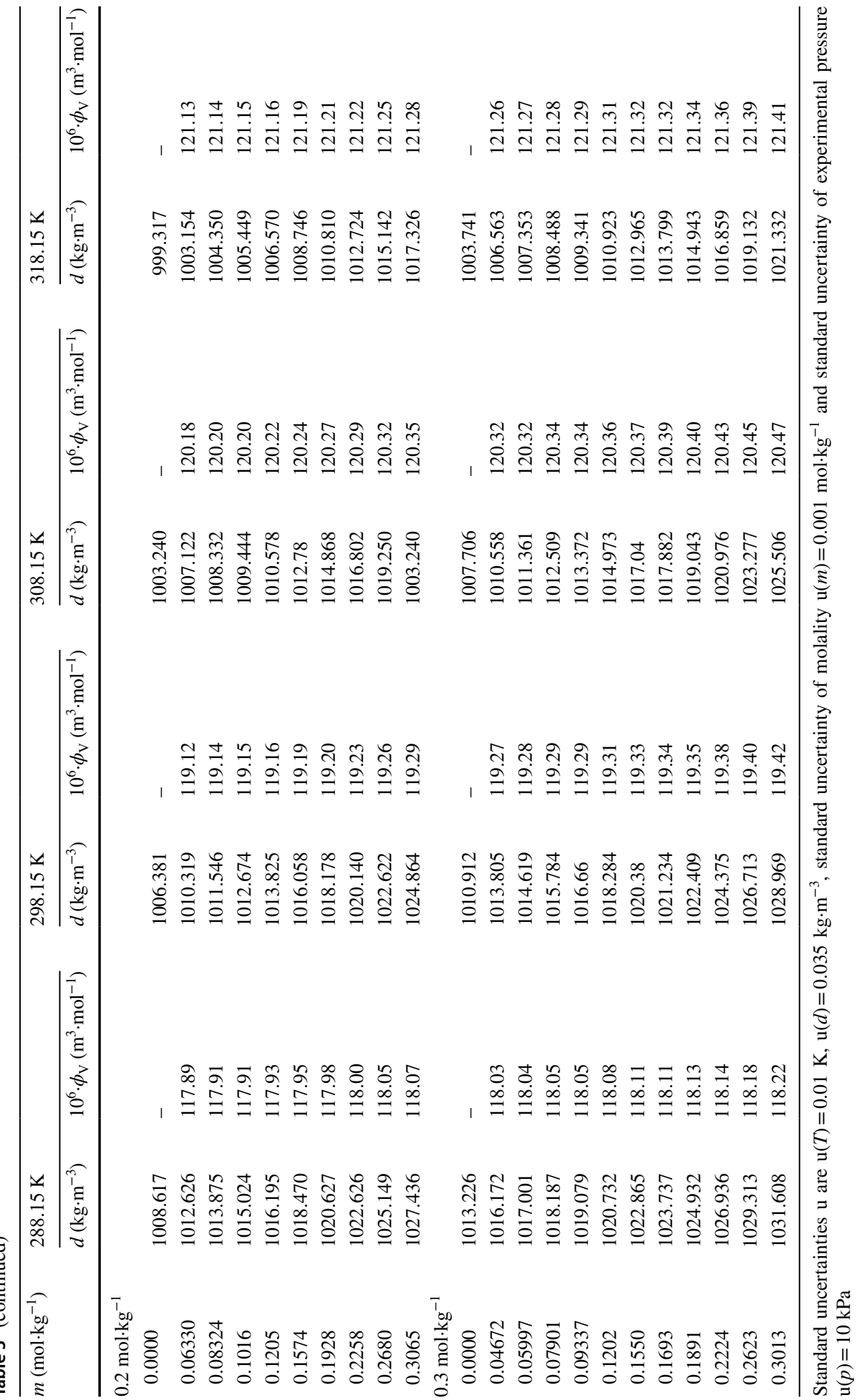




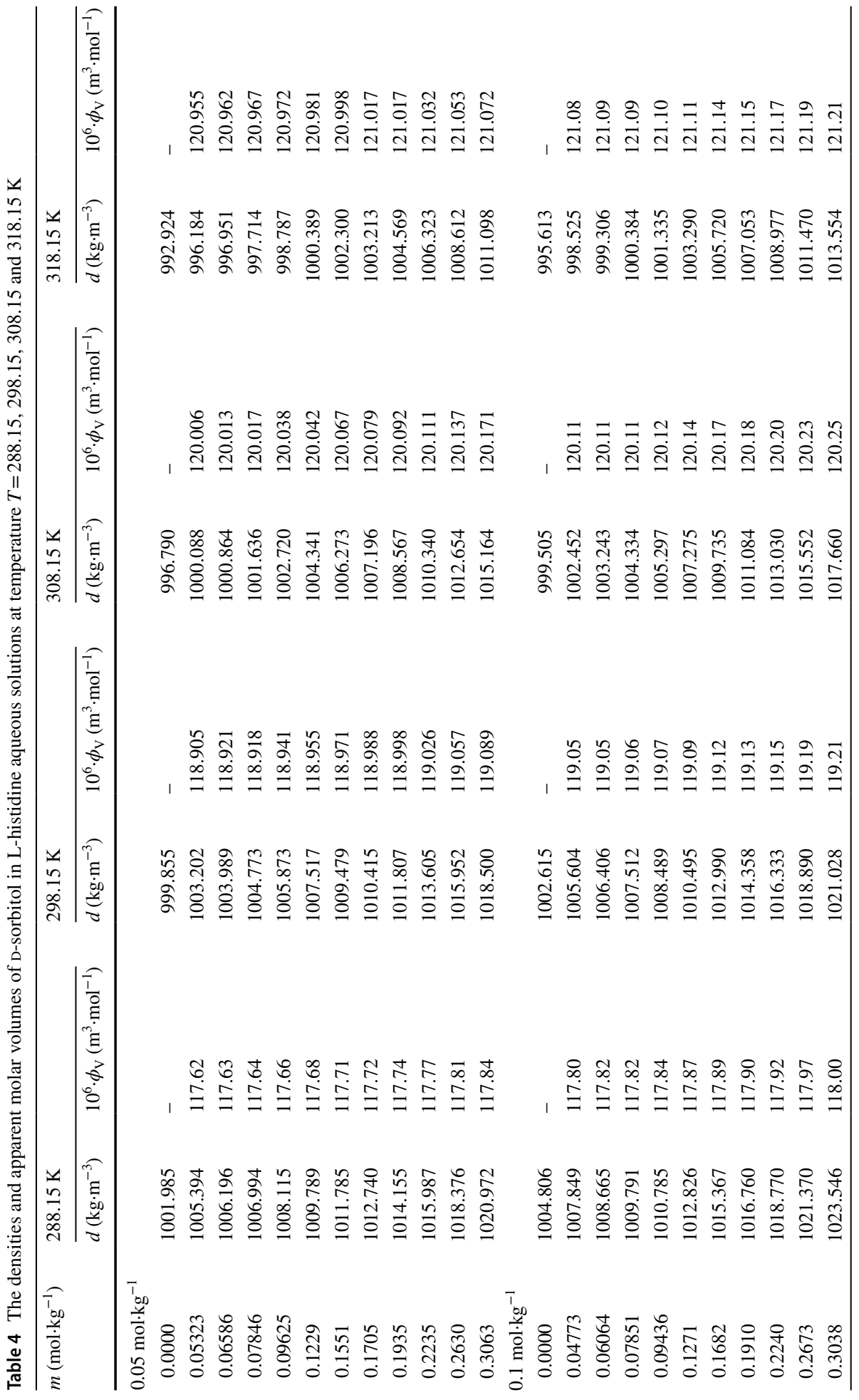




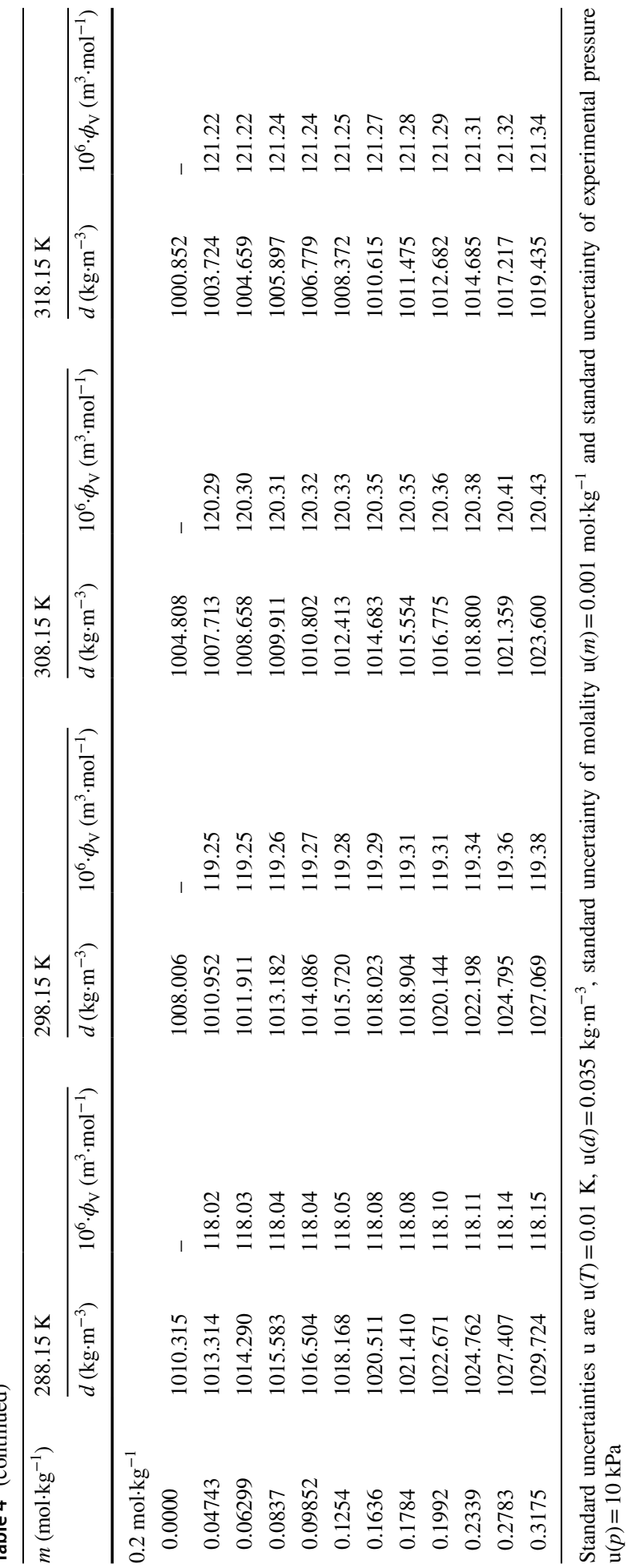




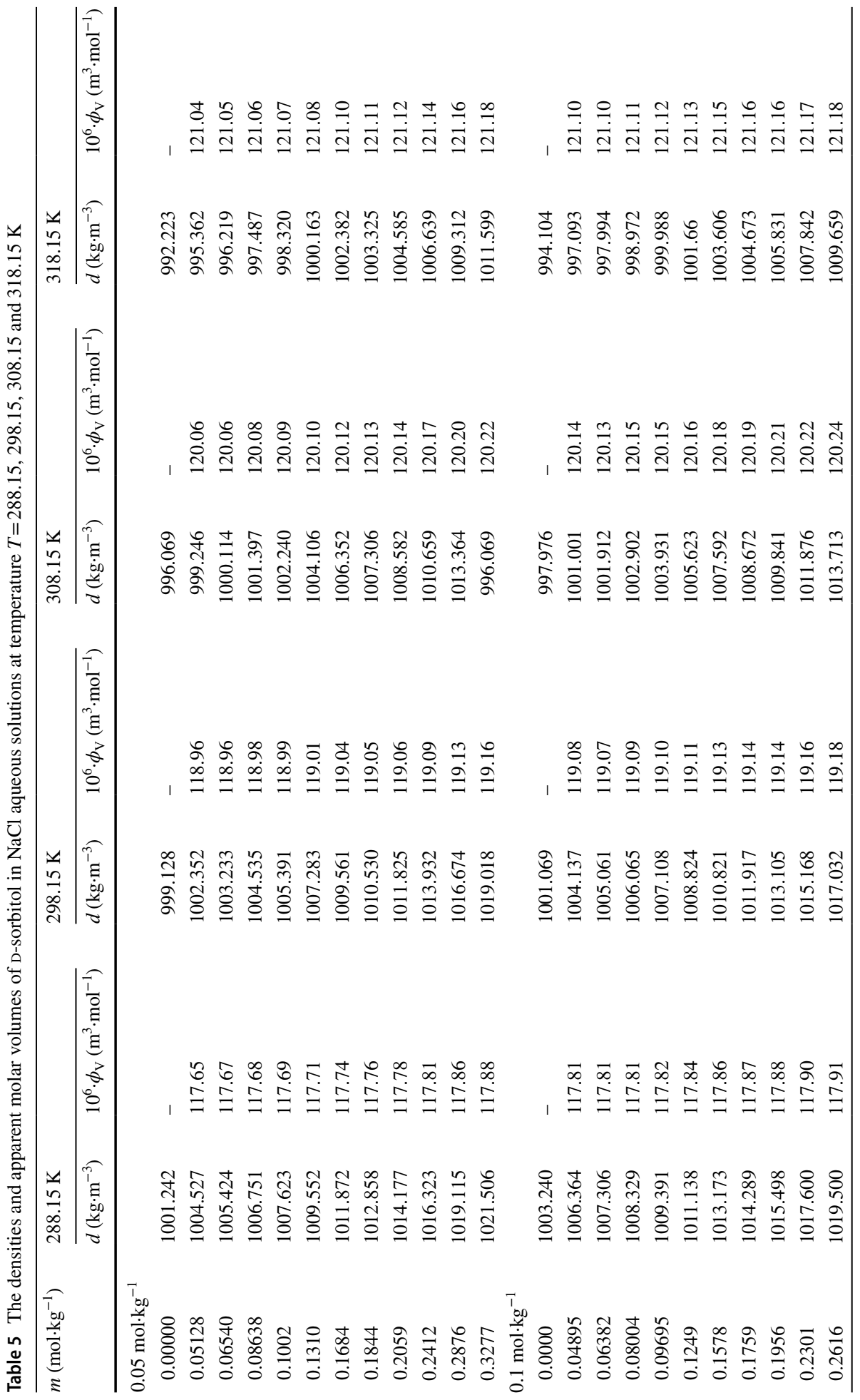




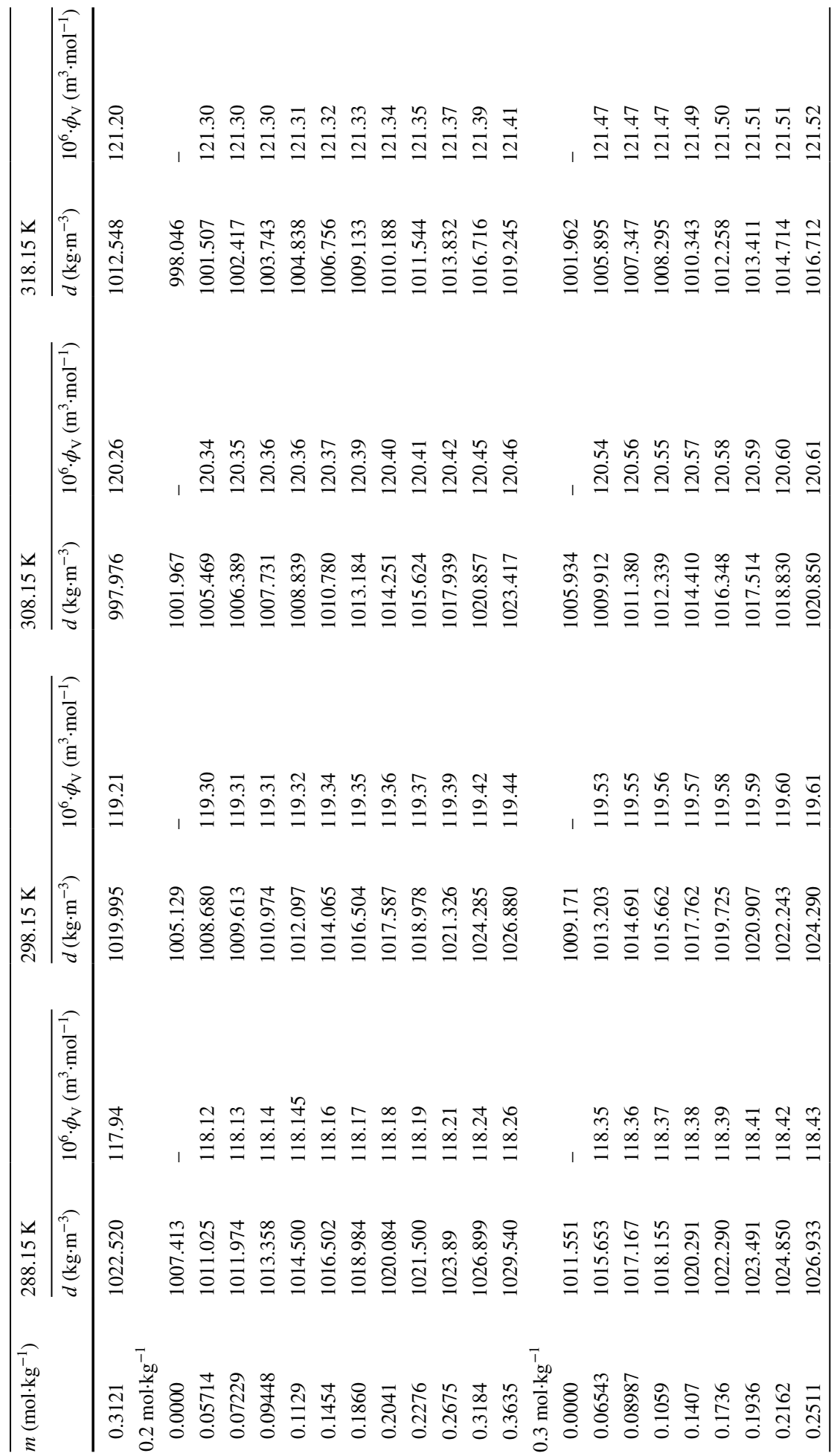




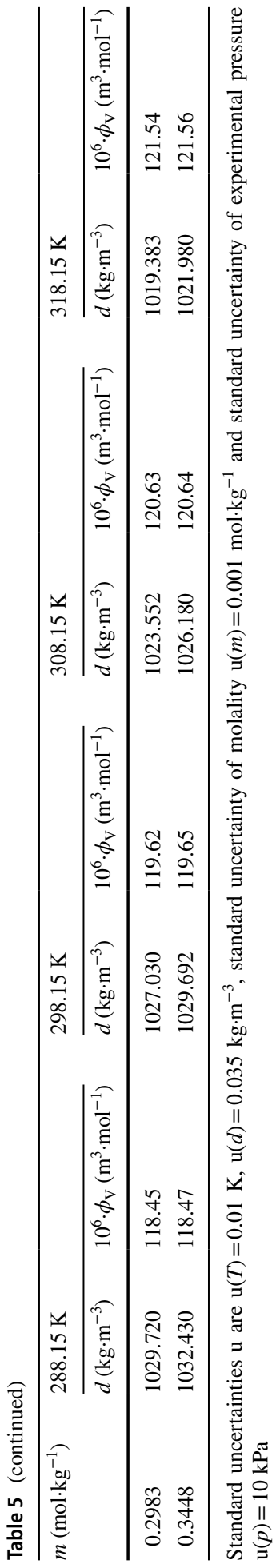


Fig. 2 The concentration dependencies of the apparent molar volume of D-sorbitol in $0.3 \mathrm{~mol} \cdot \mathrm{kg}^{-1}$ L-alanine at temperatures between 288.15 and $318.15 \mathrm{~K}: T=288.15 \mathrm{~K}$ (filled squares), $T=298.15 \mathrm{~K}$ (filled circle), $T=308.15 \mathrm{~K}$ (filled triangle) and $T=318.15 \mathrm{~K}$ (filled inverted triangle)

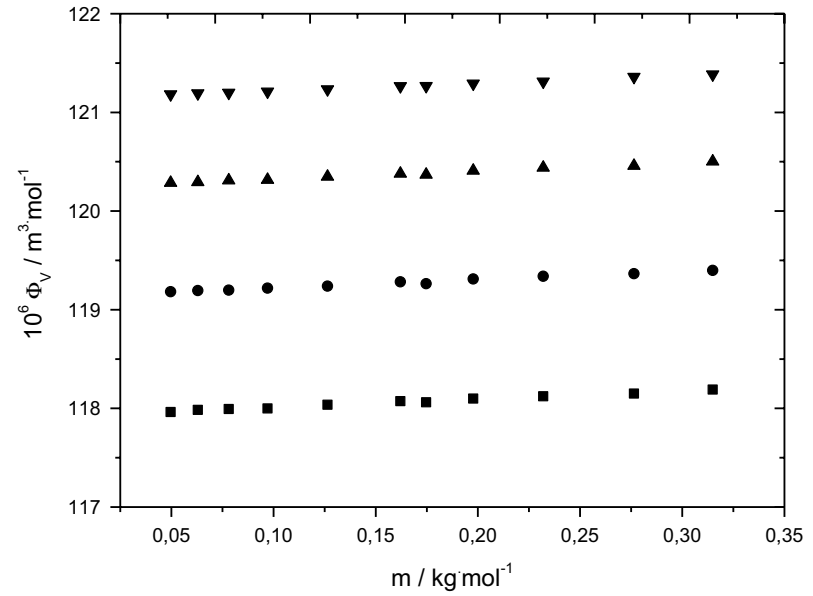

chloride. Irrespective of temperature, the increase in density resulting from increased concentration of D-sorbitol is greatest in the case of solutions in water. The greater the amount of amino acid or $\mathrm{NaCl}$ in the solution, the smaller is the increase. Moreover, with increasing temperature the observed effect, i.e. the increase in density with increasing concentration of D-sorbitol, becomes less pronounced. For all the systems studied, the density decreases with an increase in temperature.

The corresponding values of the apparent molar volumes $\phi_{\mathrm{V}}$ of D-sorbitol in the ternary systems were calculated from the densities of the solutions using the following equation:

$$
\phi_{\mathrm{V}}=\frac{\left(d_{0}-d\right)}{m d d_{0}}+\frac{M_{2}}{d}
$$

where $m$ denotes the molality of solution, $d$ and $d_{0}$ are densities of solution and solvent, respectively, and $M_{2}$ is the molar mass of the solute.

Figure 2 presents, as an example, the concentration dependencies of the apparent molar volumes of D-sorbitol in $0.3 \mathrm{~mol} \cdot \mathrm{kg}^{-1} \mathrm{~L}$-alanine at temperatures between 288.15 and $318.15 \mathrm{~K}$. As seen from the plots, the relationship is linear across the whole D-sorbitol molality range and the whole temperature range studied. Therefore, the limiting apparent molar volumes $\phi_{\mathrm{V}}^{0}$ were evaluated by extrapolating the respective plots to infinite dilution using the equation:

$$
\phi_{\mathrm{V}}=\phi_{\mathrm{V}}^{0}+S_{\mathrm{V}} m
$$

The parameters of Eq. 2 and their standard deviations $\sigma$ are given in Tables 6, 7, 8, and 9. Table 6 includes literature values of the limiting apparent molar volumes of D-sorbitol in water [18-20]. As is seen, the data from the present study shows good agreement with those in the literature. Almost no data for $\phi_{\mathrm{V}}^{0}$ in the presence of $\mathrm{NaCl}$ or amino acids are available for comparison. Exceptions include volumetric data for D-sorbitol in aqueous 2 and $4 \mathrm{~mol} \cdot \mathrm{kg}^{-1} \mathrm{NaCl}$ at $298.15 \mathrm{~K}$ reported by Jasra and Ahluwalia and the data for (L-alanine + sorbitol + water) ternary solutions obtained by Jha and Kishore and by Ren et al. [16, $17,21]$. However, the authors measured the densities of L-alanine in fixed concentrations of aqueous D-sorbitol, not D-sorbitol in fixed concentrations of aqueous L-alanine as in the present study. Moreover, different temperature ranges and distinctly higher concentrations of D-sorbitol were studied. Thus, direct comparison of the results is impossible. 
Table 6 The coefficients of Eq. 2 with the corresponding residual standard deviations $\sigma$ for D-sorbitol in L-alanine aqueous solutions at temperatures $T=288.15,298.15,308.15$ and $318.15 \mathrm{~K}$

\begin{tabular}{|c|c|c|c|}
\hline$T(K)$ & $10^{6} \cdot \phi_{\mathrm{V}}^{0}\left(\mathrm{~m}^{3} \cdot \mathrm{mol}^{-1}\right)$ & $10^{6} S_{\mathrm{V}}\left(\mathrm{m}^{3} \cdot \mathrm{kg} \cdot \mathrm{mol}^{-2}\right)$ & $10^{6} \sigma\left(\mathrm{m}^{3} \cdot \mathrm{mol}^{-1}\right)$ \\
\hline \multicolumn{4}{|l|}{ Water } \\
\hline 288.15 & $117.38 \pm 0.007\left(116.94^{\mathrm{a}}, 116.88^{\mathrm{b}}, 117.82^{\mathrm{c}}\right)$ & $1.06 \pm 0.034$ & 0.009 \\
\hline 298.15 & $118.68 \pm 0.005\left(118.62^{\mathrm{a}}, 118.97^{\mathrm{b}} .119 .15^{\mathrm{c}}\right)$ & $0.94 \pm 0.020$ & 0.004 \\
\hline 308.15 & $119.82 \pm 0.007\left(119.95^{\mathrm{a}}, 119.68^{\mathrm{b}}\right)$ & $0.83 \pm 0.028$ & 0.006 \\
\hline 318.15 & $120.84 \pm 0.008\left(121.13^{\mathrm{a}}, 121.06^{\mathrm{b}}\right)$ & $0.66 \pm 0.022$ & 0.005 \\
\hline \multicolumn{4}{|c|}{0.05 L-alanine } \\
\hline 288.15 & $117.46 \pm 0.009$ & $1.17 \pm 0.030$ & 0.007 \\
\hline 298.15 & $118.73 \pm 0.006$ & $1.01 \pm 0.032$ & 0.007 \\
\hline 308.15 & $119.86 \pm 0.005$ & $0.97 \pm 0.025$ & 0.006 \\
\hline 318.15 & $120.87 \pm 0.004$ & $0.74 \pm 0.018$ & 0.004 \\
\hline \multicolumn{4}{|c|}{0.1 L-alanine } \\
\hline 288.15 & $117.65 \pm 0.008$ & $1.00 \pm 0.025$ & 0.006 \\
\hline 298.15 & $118.93 \pm 0.008$ & $0.99 \pm 0.031$ & 0.007 \\
\hline 308.15 & $120.00 \pm 0.008$ & $0.97 \pm 0.022$ & 0.005 \\
\hline 318.15 & $120.98 \pm 0.004$ & $0.95 \pm 0.020$ & 0.005 \\
\hline \multicolumn{4}{|c|}{0.2 L-alanine } \\
\hline 288.15 & $117.76 \pm 0.008$ & $0.89 \pm 0.024$ & 0.006 \\
\hline 298.15 & $119.04 \pm 0.004$ & $0.81 \pm 0.021$ & 0.005 \\
\hline 308.15 & $120.10 \pm 0.008$ & $0.77 \pm 0.022$ & 0.006 \\
\hline 318.15 & $121.03 \pm 0.009$ & $0.75 \pm 0.031$ & 0.007 \\
\hline \multicolumn{4}{|c|}{0.3 L-alanine } \\
\hline 288.15 & $117.93 \pm 0.008$ & $0.84 \pm 0.024$ & 0.005 \\
\hline 298.15 & $119.14 \pm 0.006$ & $0.83 \pm 0.023$ & 0.006 \\
\hline 308.15 & $120.24 \pm 0.007$ & $0.81 \pm 0.022$ & 0.006 \\
\hline 318.15 & $121.14 \pm 0.004$ & $0.77 \pm 0.021$ & 0.005 \\
\hline
\end{tabular}

${ }^{\mathrm{a}}$ Ref. [18]

${ }^{\mathrm{b}}$ Ref. [19]

${ }^{\mathrm{c}}$ Ref. [20]

As can be seen from Tables 2, 3, 4 and 5 and from Fig. 2, the apparent molar volume increases with increasing molality of sugar alcohol and also with the amount of co-solute and with temperature. Irrespective of temperature and molality of amino acid or $\mathrm{NaCl}$, the concentration dependence of the apparent molar volume of D-sorbitol is very small and therefore the standard deviations of the experimental slope $S_{\mathrm{V}}$ are relatively high. However, a decrease of $S_{\mathrm{V}}$ with temperature and co-solute concentration can be observed. The results indicate that increasing temperature and increasing molality of amino acid or $\mathrm{NaCl}$ make the solute-solute interactions weaker. Additionally, the values of the experimental slope for the same molality of co-solute and the same temperature follow the following order:

\section{L-alanine $>$ L-cysteine $>$ L-histidine $>$ sodium chloride}

indicating that solute-solute interactions are weakest in the (D-sorbitol $+\mathrm{NaCl}+$ water) ternary system. 
Table 7 The coefficients of Eq. 2 with the corresponding residual standard deviations $\sigma$ for D-sorbitol in L-cysteine aqueous solution at temperature $T=288.15,298.15,308.15$ and $318.15 \mathrm{~K}$

\begin{tabular}{llll}
\hline$T / \mathrm{K} \quad 10^{6} \cdot \phi_{\mathrm{V}}^{0}\left(\mathrm{~m}^{3} \cdot \mathrm{mol}^{-1}\right)$ & $\begin{array}{l}10^{6} \cdot S_{\mathrm{V}} \\
\left(\mathrm{m}^{3} \cdot \mathrm{kg} \cdot \mathrm{mol}^{-2}\right)\end{array}$ & $10^{6} \cdot \sigma\left(\mathrm{m}^{3} \cdot \mathrm{mol}^{-1}\right)$ \\
\end{tabular}

\begin{tabular}{llll}
\hline 0.05 L-cysteine & & \\
288.15 & $117.52 \pm 0.004$ & $0.87 \pm 0.010$ & 0.003 \\
298.15 & $118.85 \pm 0.006$ & $0.85 \pm 0.018$ & 0.004 \\
308.15 & $119.95 \pm 0.006$ & $0.74 \pm 0.026$ & 0.006 \\
318.15 & $120.93 \pm 0.005$ & $0.70 \pm 0.027$ & 0.006 \\
0.1 L-cysteine & & & \\
288.15 & $117.71 \pm 0.009$ & $0.79 \pm 0.027$ & 0.007 \\
298.15 & $118.98 \pm 0.007$ & $0.74 \pm 0.021$ & 0.005 \\
308.15 & $120.00 \pm 0.007$ & $0.70 \pm 0.014$ & 0.003 \\
318.15 & $121.00 \pm 0.008$ & $0.66 \pm 0.026$ & 0.006 \\
0.2 L-cysteine & & & \\
288.15 & $117.84 \pm 0.005$ & $0.74 \pm 0.029$ & 0.007 \\
298.15 & $119.08 \pm 0.005$ & $0.69 \pm 0.021$ & 0.004 \\
308.15 & $120.14 \pm 0.003$ & $0.67 \pm 0.015$ & 0.003 \\
318.15 & $121.09 \pm 0.005$ & $0.62 \pm 0.016$ & 0.003 \\
0.3 L-cysteine & & & \\
288.15 & $117.99 \pm 0.005$ & $0.73 \pm 0.024$ & 0.005 \\
298.15 & $119.24 \pm 0.003$ & $0.61 \pm 0.017$ & 0.003 \\
308.15 & $120.29 \pm 0.005$ & $0.61 \pm 0.021$ & 0.005 \\
318.15 & $121.23 \pm 0.008$ & $0.57 \pm 0.015$ & 0.004 \\
\hline \multicolumn{5}{l}{} & &
\end{tabular}

Table 8 The coefficients of Eq. 2 with the corresponding residual standard deviations $\sigma$ for D-sorbitol in L-histidine aqueous solution at temperature $T=288.15,298.15,308.15$ and $318.15 \mathrm{~K}$

\begin{tabular}{llll}
\hline$T / \mathrm{K}$ & $10^{6} \cdot \phi_{\mathrm{V}}^{0}\left(\mathrm{~m}^{3} \cdot \mathrm{mol}^{-1}\right)$ & $10^{6} S_{\mathrm{V}}\left(\mathrm{m}^{3} \cdot \mathrm{kg} \cdot \mathrm{mol}^{-2}\right)$ & $10^{6} \sigma\left(\mathrm{m}^{3} \cdot \mathrm{mol}^{-1}\right)$ \\
\hline 0.05 L-histidine & & & 0.003 \\
288.15 & $117.57 \pm 0.007$ & $0.86 \pm 0.019$ & 0.005 \\
298.15 & $118.87 \pm 0.006$ & $0.71 \pm 0.021$ & 0.004 \\
308.15 & $119.97 \pm 0.004$ & $0.64 \pm 0.018$ & 0.003 \\
318.15 & $120.93 \pm 0.004$ & $0.46 \pm 0.015$ & \\
0.1 L-histidine & & & 0.006 \\
288.15 & $117.77 \pm 0.005$ & $0.73 \pm 0.029$ & 0.003 \\
298.15 & $119.02 \pm 0.006$ & $0.62 \pm 0.015$ & 0.005 \\
308.15 & $120.07 \pm 0.004$ & $0.59 \pm 0.022$ & 0.003 \\
318.15 & $121.05 \pm 0.005$ & $0.51 \pm 0.017$ & \\
0.2 L-histidine & & & 0.004 \\
288.15 & $117.99 \pm 0.005$ & $0.52 \pm 0.015$ & 0.003 \\
298.15 & $119.22 \pm 0.004$ & $0.50 \pm 0.014$ & 0.004 \\
308.15 & $120.27 \pm 0.005$ & $0.49 \pm 0.016$ & 0.004 \\
318.15 & $121.20 \pm 0.006$ & $0.46 \pm 0.018$ & \\
\hline
\end{tabular}


Table 9 The coefficients of Eq. 2 with the corresponding residual standard deviations $\sigma$ for D-sorbitol in $\mathrm{NaCl}$ aqueous solution at temperature $T=288.15,298.15,308.15$ and $318.15 \mathrm{~K}$

\begin{tabular}{|c|c|c|c|}
\hline$T / \mathrm{K}$ & $10^{6} \cdot \phi_{\mathrm{V}}^{0}\left(\mathrm{~m}^{3} \cdot \mathrm{mol}^{-1}\right)$ & $10^{6} \cdot S_{\mathrm{V}}\left(\mathrm{m}^{3} \cdot \mathrm{kg} \cdot \mathrm{mol}^{-2}\right)$ & $10^{6} \sigma\left(\mathrm{m}^{3} \cdot \mathrm{mol}^{-1}\right)$ \\
\hline \multicolumn{4}{|c|}{$0.05 \mathrm{NaCl}$} \\
\hline 288.15 & $117.61 \pm 0.008$ & $0.84 \pm 0.024$ & 0.006 \\
\hline 298.15 & $118.92 \pm 0.006$ & $0.73 \pm 0.016$ & 0.004 \\
\hline 308.15 & $120.03 \pm 0.006$ & $0.58 \pm 0.020$ & 0.004 \\
\hline 318.15 & $121.01 \pm 0.005$ & $0.52 \pm 0.012$ & 0.003 \\
\hline \multicolumn{4}{|l|}{$0.1 \mathrm{NaCl}$} \\
\hline 288.15 & $117.78 \pm 0.005$ & $0.52 \pm 0.021$ & 0.005 \\
\hline 298.15 & $119.05 \pm 0.004$ & $0.50 \pm 0.012$ & 0.003 \\
\hline 308.15 & $120.11 \pm 0.005$ & $0.49 \pm 0.018$ & 0.004 \\
\hline 318.15 & $121.08 \pm 0.005$ & $0.39 \pm 0.017$ & 0.004 \\
\hline \multicolumn{4}{|l|}{$0.2 \mathrm{NaCl}$} \\
\hline 288.15 & $118.09 \pm 0.006$ & $0.48 \pm 0.015$ & 0.004 \\
\hline 298.15 & $119.28 \pm 0.005$ & $0.43 \pm 0.016$ & 0.004 \\
\hline 308.15 & $120.32 \pm 0.005$ & $0.40 \pm 0.016$ & 0.004 \\
\hline 318.15 & $121.27 \pm 0.006$ & $0.38 \pm 0.015$ & 0.004 \\
\hline \multicolumn{4}{|l|}{$0.3 \mathrm{NaCl}$} \\
\hline 288.15 & $118.32 \pm 0.004$ & $0.43 \pm 0.010$ & 0.002 \\
\hline 298.15 & $119.51 \pm 0.007$ & $0.38 \pm 0.010$ & 0.003 \\
\hline 308.15 & $120.52 \pm 0.004$ & $0.36 \pm 0.015$ & 0.003 \\
\hline 318.15 & $121.44 \pm 0.007$ & $0.32 \pm 0.015$ & 0.003 \\
\hline
\end{tabular}

An examination of the data also reveals that the limiting apparent molar volumes of Dsorbitol are positive and increase with increasing molality of amino acid or sodium chloride, as well as with increasing temperature. The limiting apparent molar expansibilities $\left(\partial \phi_{\mathrm{V}}^{0} / \partial T\right)_{p}$ and their second derivatives $\left(\partial^{2} \phi_{\mathrm{V}}^{0} / \partial T^{2}\right)_{p}$, presented in Table 10, were calculated by fitting the $\phi_{\mathrm{V}}^{0}$ data, as a function of temperature, into the following equation:

$$
\phi_{\mathrm{V}}^{0}=A_{0}+A_{1} T+A_{2} T^{2}
$$

using the least-squares method, where $A_{0}, A_{1}$ and $A_{2}$ are constants. As is seen, the values of the limiting apparent molar expansibilities for all the systems studied are positive. This suggests that the temperature increase causes the liberation of solvent molecules from the solvation layer of D-sorbitol, thereby increasing the total volume of the system. Moreover, the fact that the limiting apparent molar expansibility values decrease with rising temperature indicates that at higher temperatures this effect is weaker.

The calculated values of the second derivate $\left(\partial^{2} \phi_{\mathrm{V}}^{0} / \partial T^{2}\right)_{p}$ are negative. Therefore, according to Hepler's method of examining the sign of the second derivate for solute in terms of the structure-making or structure-breaking nature of the solute in mixed solvent systems, D-sorbitol is a structure breaker in water, as well as in aqueous amino acid and sodium chloride [22].

Figure 3 presents the limiting apparent molar volumes of transfer of D-sorbitol, $\Delta_{\mathrm{t}} \phi_{\mathrm{V}}^{0}$, versus molalities of L-alanine, L-cysteine, L-histidine and $\mathrm{NaCl}$. The values of $\Delta_{\mathrm{t}} \phi_{\mathrm{V}}^{0}$ from aqueous to aqueous co-solute solutions were calculated as: 
Table 10 Limiting apparent molar expansibilities and the second-order derivatives of $\phi_{\mathrm{V}}$ for D-sorbitol in L-aniline, L-cysteine, L-histidine and $\mathrm{NaCl}$ aqueous solution at temperatures $T=288.15,298.15,308.15$ and $318.15 \mathrm{~K}$

\begin{tabular}{|c|c|c|c|c|c|c|}
\hline \multirow{2}{*}{$\begin{array}{l}m_{\mathrm{b}}\left(\mathrm{mol} \cdot \mathrm{kg}^{-1}\right) \\
T / \mathrm{K}\end{array}$} & \multicolumn{4}{|c|}{$10^{6} \cdot\left(\partial \phi_{\mathrm{V}}^{0} / \partial T\right)_{p}\left(\mathrm{~m}^{3} \cdot \mathrm{K}^{-1} \cdot \mathrm{mol}^{-1}\right)$} & \multirow{2}{*}{$\begin{array}{l}10^{6} \cdot \sigma \\
\left(\mathrm{m}^{3} \cdot \mathrm{K}^{-1} \cdot \mathrm{mol}^{-1}\right)\end{array}$} & \multirow{2}{*}{$\begin{array}{l}10^{6} \cdot\left(\partial^{2} \phi_{\mathrm{V}}^{0} / \partial T^{2}\right) \\
\left(\mathrm{m}^{3} \cdot \mathrm{K}^{-2} \cdot \mathrm{mol}^{-1}\right)\end{array}$} \\
\hline & 288.15 & 298.15 & 308.15 & 318.15 & & \\
\hline \multicolumn{7}{|l|}{ Water } \\
\hline 0 & 0.136 & 0.122 & 0.109 & 0.095 & 0.0064 & -0.0014 \\
\hline \multicolumn{7}{|l|}{ L-alanine } \\
\hline 0.05 & 0.134 & 0.120 & 0.107 & 0.094 & 0.0024 & -0.0013 \\
\hline 0.1 & 0.136 & 0.119 & 0.102 & 0.086 & 0.0029 & -0.0017 \\
\hline 0.2 & 0.135 & 0.117 & 0.100 & 0.082 & 0.0088 & -0.0018 \\
\hline 0.3 & 0.131 & 0.115 & 0.100 & 0.084 & 0.014 & -0.0016 \\
\hline \multicolumn{7}{|l|}{ L-cysteine } \\
\hline 0.05 & 0.140 & 0.122 & 0.104 & 0.087 & 0.017 & -0.0018 \\
\hline 0.1 & 0.133 & 0.117 & 0.101 & 0.085 & 0.011 & -0.0016 \\
\hline 0.2 & 0.130 & 0.115 & 0.101 & 0.086 & 0.010 & -0.0015 \\
\hline 0.3 & 0.130 & 0.115 & 0.100 & 0.085 & 0.013 & -0.0015 \\
\hline \multicolumn{7}{|l|}{ L-histidine } \\
\hline 0.05 & 0.137 & 0.120 & 0.103 & 0.087 & 0.0062 & -0.0017 \\
\hline 0.1 & 0.129 & 0.116 & 0.102 & 0.089 & 0.016 & -0.0013 \\
\hline 0.2 & 0.129 & 0.114 & 0.099 & 0.085 & 0.0075 & -0.0015 \\
\hline \multicolumn{7}{|l|}{$\mathrm{NaCl}$} \\
\hline 0.05 & 0.138 & 0.121 & 0.105 & 0.089 & 0.010 & -0.0016 \\
\hline 0.1 & 0.132 & 0.117 & 0.102 & 0.087 & 0.018 & -0.0015 \\
\hline 0.2 & 0.123 & 0.112 & 0.100 & 0.088 & 0.010 & -0.0012 \\
\hline 0.3 & 0.124 & 0.110 & 0.097 & 0.084 & 0.015 & -0.0013 \\
\hline
\end{tabular}

$$
\Delta_{\mathrm{t}} \phi_{\mathrm{V}}^{0}=\phi_{\mathrm{V}}^{0}\left(\mathrm{H}_{2} \mathrm{O}+\text { co-solute }\right)-\phi_{\mathrm{V}}^{0}\left(\mathrm{H}_{2} \mathrm{O}\right)
$$

It has been established by Shahidi, Farrell and Edward that the limiting apparent molar volume of a hydrophilic solute in water can be divided into two terms as:

$$
\phi_{\mathrm{V}}^{0}=V_{\mathrm{int}}-n \sigma
$$

where $V_{\text {int }}$ is the intrinsic molar volume, $\sigma$ is the shrinkage in the volume due to hydrogen bonding between water and the hydrophilic solute and $n$ denotes the number of hydrogen bonding sites [23]. Moreover, the intrinsic molar volume $V_{\text {int }}$ consists of the van der Waals volume and the associated void or empty volume. For dilute solutions, it is reasonable to assume that the intrinsic molar volume is nearly constant with respect to concentration. Thus, the observed positive volume change accompanying the transfer of D-sorbitol from water to aqueous amino acid or $\mathrm{NaCl}$ solution may result from a decrease in the shrinkage in volume because of solute co-solute interactions. Additionally, the increasing values of the limiting apparent molar volumes of transfer with molality of $\mathrm{NaCl}$ or amino acid reveal that the interactions resulting in the dehydration of the sugar alcohol increase with the concentration of co-solute. 


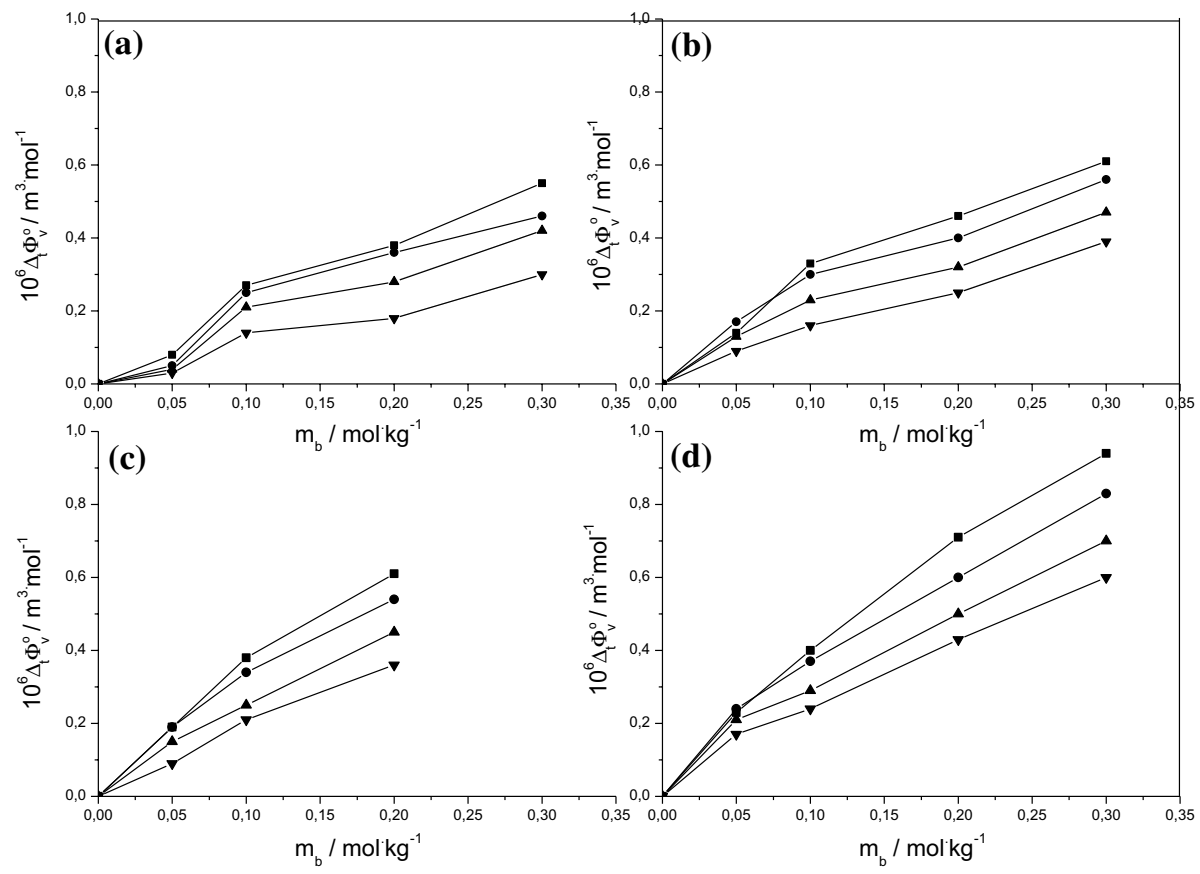

Fig. 3 The limiting apparent molar volumes of transfer of D-sorbitol versus molalities of L-alanine (a), L-cysteine (b), L-histidine (c) and $\mathrm{NaCl}$ (d). Symbols the same as in Fig. 1

As can be seen from Fig. 3, at all temperatures studied for all systems, the values of the limiting apparent molar volumes of transfer are in the following ascending order:

\section{L-alanine > L-cysteine > L-histidine > sodium chloride}

indicating that the strongest solute co-solute interactions occur in the (D-sorbitol $+\mathrm{NaCl}+$ water) ternary system.

The interactions between D-sorbitol and L-alanine, L-cysteine, L-histidine and $\mathrm{NaCl}$ in aqueous solutions can also be explained on the basis of the co-sphere overlap model [24]. According to the model, when two molecules approach each other, their hydration cospheres overlap and the physico-chemical properties of the solution, such as limiting apparent molar volume, change. The possible types of interactions between solute and co-solute are:

(1) hydrophilic-ionic interactions between hydrophilic groups of solute and ions of cosolute;

(2) hydrophobic-ionic interactions between the hydrophobic alkyl chain of solute and ions of co-solute;

(3) hydrophilic-hydrophilic interactions between the hydrophilic groups of solute and the hydrophilic groups of co-solute;

(4) hydrophobic-hydrophobic interactions between the hydrophobic alkyl chain of solute and the hydrophobic alkyl chain of co-solute;

(5) hydrophobic-hydrophilic interactions between the hydrophobic alkyl chain of solute and the hydrophilic groups of co-solute. 
Fig. 4 The limiting apparent molar volumes of transfer of D-sorbitol versus molalities of L-alanine (filled circles) and $\mathrm{NaCl}$ (filled squares) together with the literature data for D-sorbitol versus molalities of L-glycine (filled triangle) and $\mathrm{NaCl}$ (open squares) at temperature $298.15 \mathrm{~K}[18,21]$

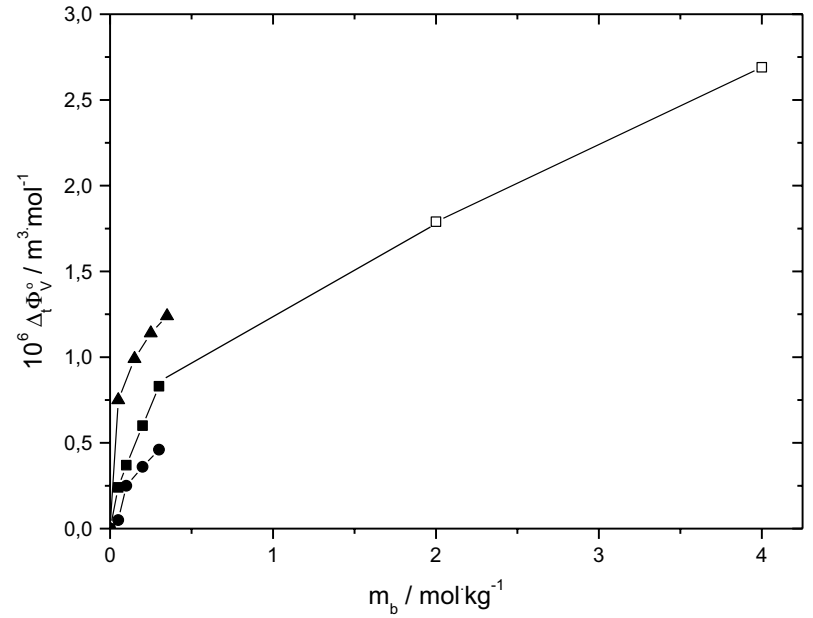

It is obvious that in solutions of D-sorbitol in aqueous amino acids all five types of interactions are possible, while in solutions of D-sorbitol in aqueous sodium chloride only two types of interactions, i.e. (1) and (2), can occur. Hydrophilic-ionic interactions and hydrophilic-hydrophilic interactions result in positive values of the limiting apparent molar volumes of transfer, whereas hydrophobic-ionic, hydrophobic-hydrophobic and hydrophobic-hydrophilic interactions result in negative $\Delta_{\mathrm{t}} \phi_{\mathrm{V}}^{0}$ values. The observed positive values of $\Delta_{\mathrm{t}} \phi_{\mathrm{V}}^{0}$ suggest that for D-sorbitol in aqueous $\mathrm{NaCl}$ interactions of type (1) and for D-sorbitol in aqueous amino acids interactions of types (1) and (3) are predominant.

Figure 4 presents the limiting apparent molar volumes of transfer for D-sorbitol versus molalities of L-alanine and $\mathrm{NaCl}$ at $298.15 \mathrm{~K}$ together with the literature data for D-sorbitol in aqueous L-glycine and sodium chloride $[18,21]$. For clarity, the experimental values of $\Delta_{\mathrm{t}} \phi_{\mathrm{V}}^{0}$ for D-sorbitol in aqueous L-cysteine and L- histidine solutions are not shown. As is seen from Figs. 3 and 4, D-sorbitol displays highest positive values of the limiting apparent molar volumes of transfer in aqueous L-glycine, the smallest amino acid studied, while lowest values of $\Delta_{\mathrm{t}} \phi_{\mathrm{V}}^{0}$ are observed in L-alanine, the most hydrophobic amino acid studied. Comparison of the limiting apparent molar volumes of transfer of D-sorbitol between amino acids of the same alkyl chain length, i.e. L-alanine, L-cysteine and L-histidine, indicates that $\Delta_{\mathrm{t}} \phi_{\mathrm{V}}^{0}$ is determined by the hydrophilic residues of the amino acid. According to the hydrophobicity scale of amino acids proposed by Kapcha and Rossky, L-histidine is more hydrophilic than L-cysteine. This results in stronger hydrophilic-ionic and hydrophilic-hydrophilic interactions between D-sorbitol and L-histidine than those between D-sorbitol and L-cysteine, leading to more positive values of the limiting apparent molar volumes of transfer [25].

As mentioned above, the experimental data on $\Delta_{\mathrm{t}} \phi_{\mathrm{V}}^{0}$ for D-sorbitol in aqueous sodium chloride are consistent with that in literature. Moreover, the observed values of the limiting apparent molar volumes of transfer for that system are lower than those for (D-sorbitol + L-glycine + water). This is clearly the result of the strong hydrophilic-hydrophilic interactions between D-sorbitol and L-glycine which do not take place between sugar alcohols and $\mathrm{NaCl}$.

In line with the proposition of Friedman and Krishnan, according to which the thermodynamic transfer properties of solutes in dilute aqueous solution are determined by 
solute and co-solute interactions without the consideration of solute-solute interactions, and in conformity with the McMillan-Mayer theory, the limiting apparent molar volume of transfer can be expressed as:

$$
\Delta_{\mathrm{t}} \phi_{\mathrm{V}}^{0}=2 V_{\mathrm{ab}} m_{\mathrm{b}}+3 V_{\mathrm{abb}} m_{\mathrm{b}}^{2}
$$

where $V_{\mathrm{ab}}$ and $V_{\mathrm{abb}}$ are the pairwise and triplet interaction coefficients, respectively, and $m_{\mathrm{b}}$ is the molality of the co-solute $[26,27]$. Table 11 presents the values of the volumetric interaction coefficients of D-sorbitol in aqueous L-aniline, L-cysteine, $\mathrm{L}$ - histidine and $\mathrm{NaCl}$ solutions obtained in the present study. As is seen, in all cases the pairwise interaction coefficients are positive while the triplet interaction coefficients are negative. In general, the magnitude of volume interaction coefficients decreases with rising temperature. The fact that the pairwise interaction coefficients are positive and larger in magnitude than the triplet interaction coefficients suggests that the volumetric properties of the studied solutions are determined by the strong interactions between D-sorbitol and the amino acids or sodium chloride and that these interactions dominate over triplet interactions. Moreover, the decrease of volume interaction coefficients with rising temperature indicates that pairwise interactions, as well as triplet interactions, become weaker at higher temperatures.

\subsection{Acoustic Properties}

The experimental values of molality, sound velocity and apparent molar compressibility at $298.15 \mathrm{~K}$ of the solutions of D-sorbitol in aqueous L-alanine, L-cysteine, L- histidine and $\mathrm{NaCl}$ are reported in Tables 12,13,14, and 15. As is seen, the values of sound velocity increase with increasing molality of sugar alcohol, both in water and in the aqueous solutions of amino acids or sodium chloride. This suggests that as the molality increases, intermolecular hydrogen bonds between D-sorbitol and water and intramolecular hydrogen bonds within D-sorbitol molecules themselves become stronger, resulting in a more ordered solution. Moreover, for solutions with the same molality of D-sorbitol, an increase in sound velocity with growing concentration of co-solute is also observed. This suggests that association among the molecules of the solution becomes stronger as the amount of amino acid or $\mathrm{NaCl}$ in solution increases.

The apparent molar compressibilities, $\phi_{\mathrm{KS}}$, of D-sorbitol in the ternary systems were calculated from the densities and the sound velocities of the solutions according to the equation:

$$
\phi_{\mathrm{KS}}=\frac{\left(d_{0} K_{\mathrm{S}}-d K_{\mathrm{S}}^{0}\right)}{m d d_{0}}+\frac{M_{2} K_{\mathrm{S}}}{d}
$$

where $K_{\mathrm{S}}$ and $K_{\mathrm{S}}^{0}$ denote isentropic compressibilities of the solution and solvent, respectively.

The isentropic compressibility $K_{\mathrm{S}}$ was obtained from density and sound velocity values using the Laplace equation:

$$
K_{\mathrm{S}}=\frac{1}{u^{2} d}
$$

As can be observed in Tables 12 and 15, the values of the apparent molar compressibilities are negative for all the systems studied. This indicates a decrease in compressibility 


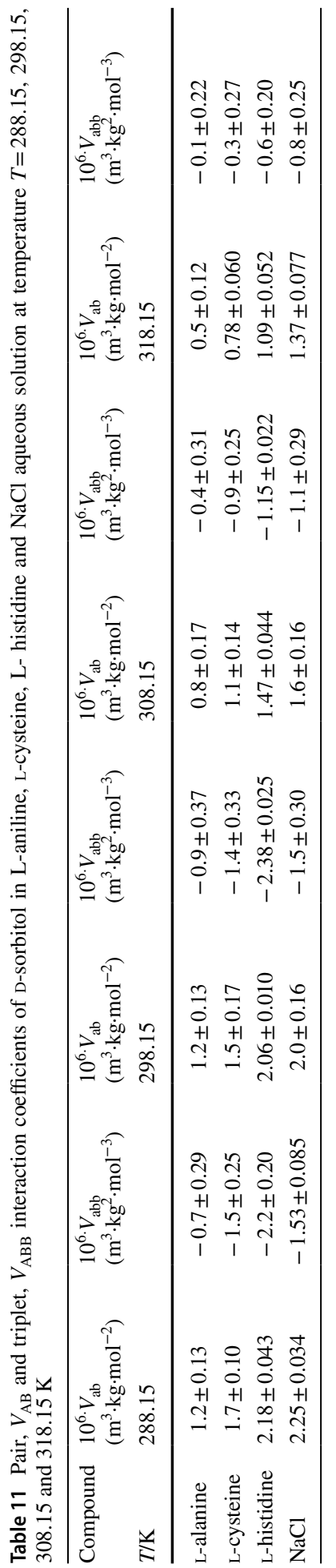




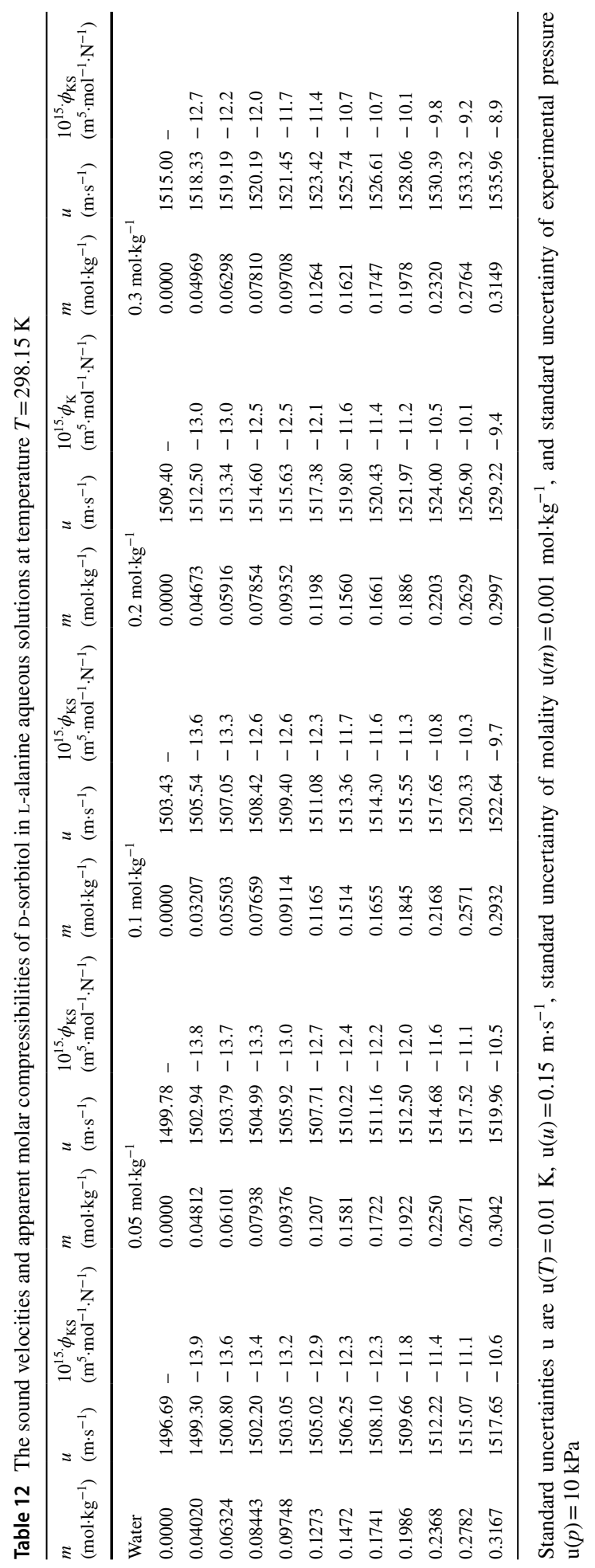




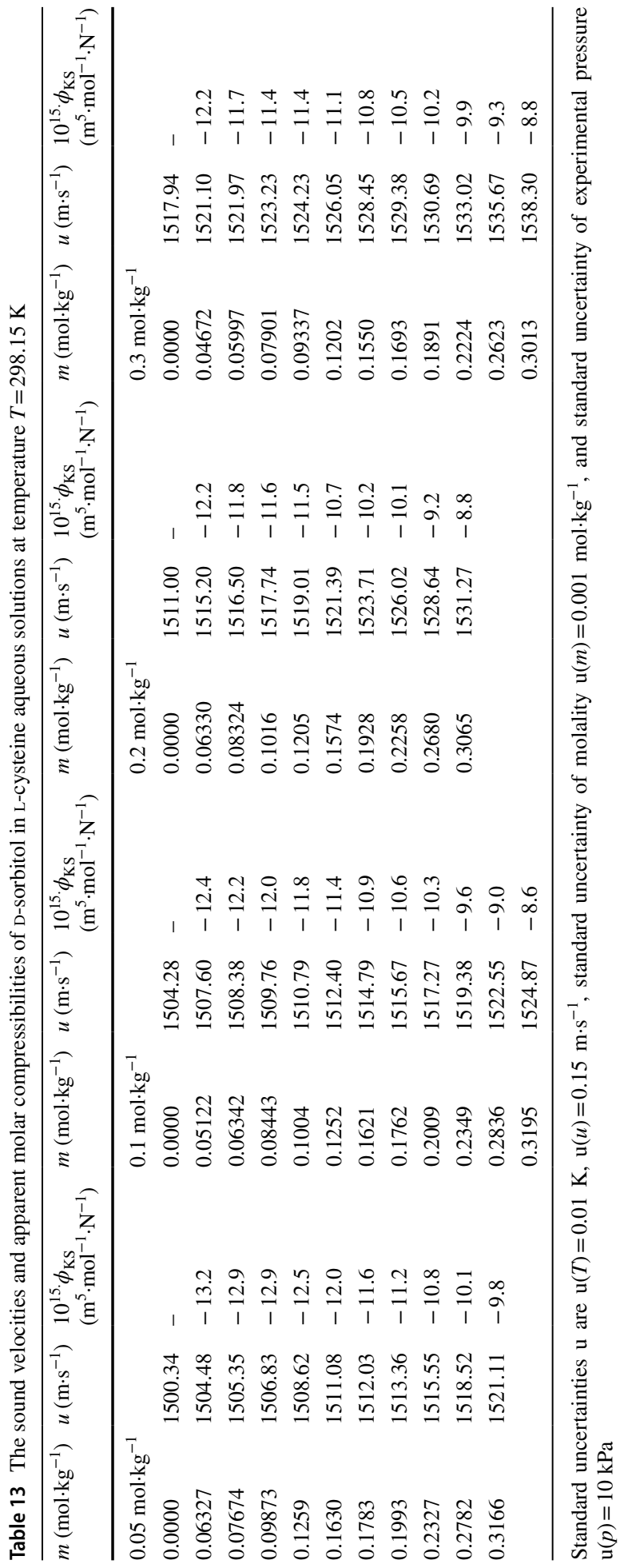




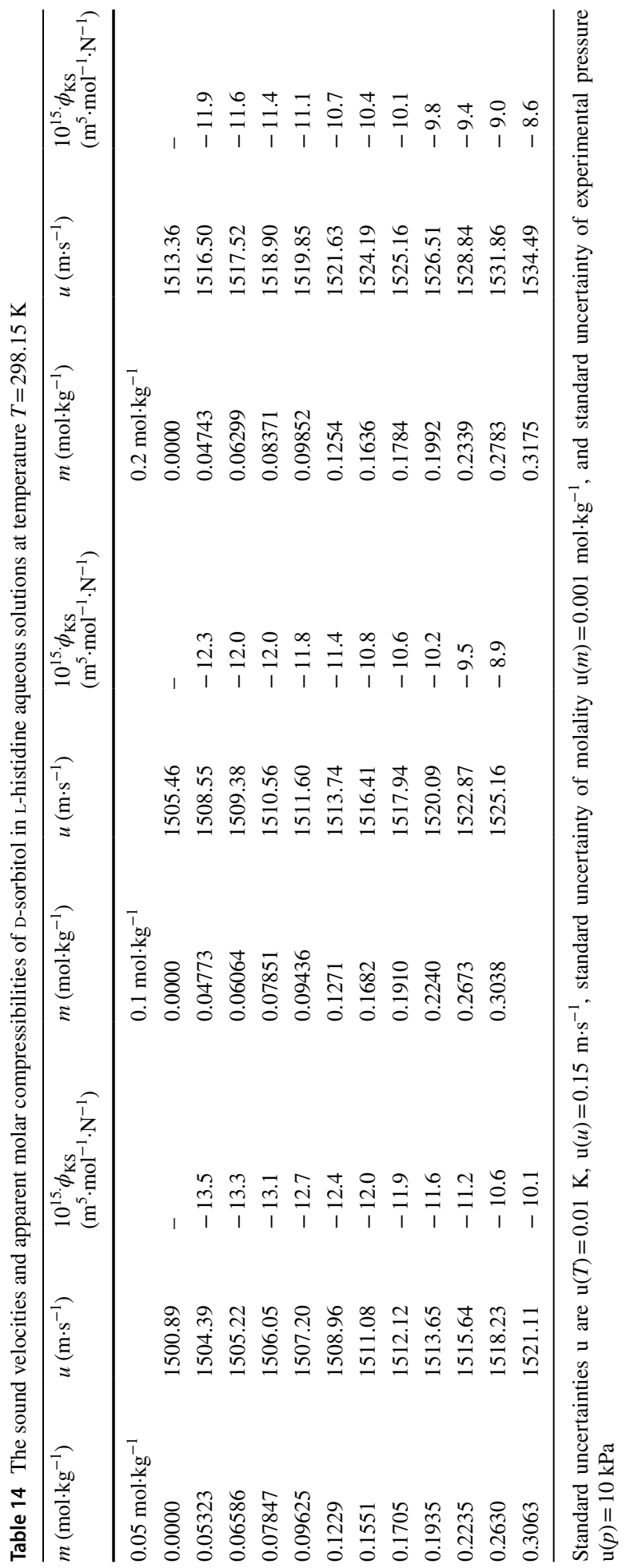




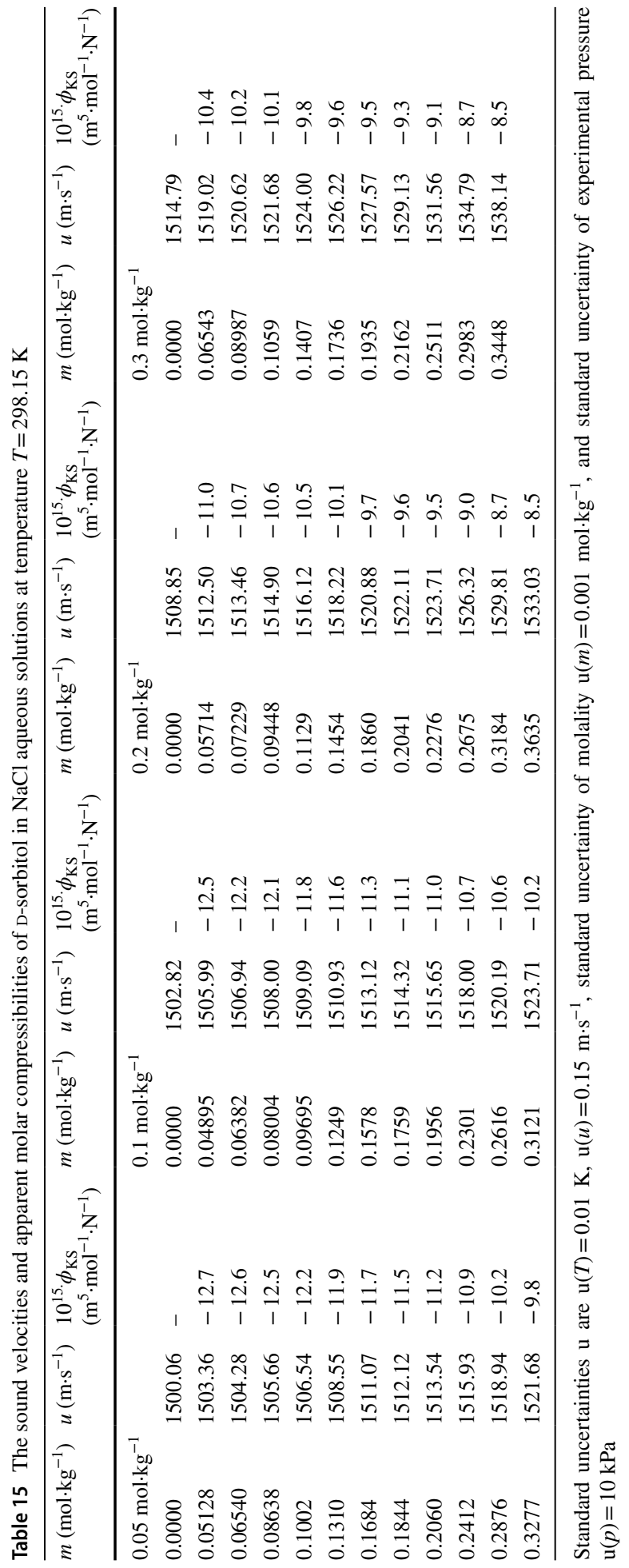


Table 16 The coefficients of Eq. 9 with the corresponding residual standard deviations $\sigma$ for D-sorbitol in L-aniline, L-cysteine, L-histidine and $\mathrm{NaCl}$ aqueous solution at $T=298.15 \mathrm{~K}$

\begin{tabular}{|c|c|c|c|}
\hline $\mathrm{m}_{\mathrm{b}}\left(\mathrm{mol} \cdot \mathrm{kg}^{-1}\right)$ & $10^{15} \phi_{\mathrm{K}}\left(\mathrm{m}^{5} \cdot \mathrm{N}^{-1} \cdot \mathrm{mol}^{-1}\right)$ & $10^{15} S_{\mathrm{k}}\left(\mathrm{m}^{5} \cdot \mathrm{kg} \cdot \mathrm{N}^{-1} \cdot \mathrm{mol}^{-2}\right)$ & $\begin{array}{l}10^{15} \sigma \\
\left(\mathrm{m}^{5} \cdot \mathrm{N}^{-1} \cdot \mathrm{mol}^{-1}\right)\end{array}$ \\
\hline \multicolumn{4}{|l|}{ Water } \\
\hline 0 & $-14.3 \pm 0.11\left(-14.29^{\mathrm{a}}\right)$ & $12.0 \pm 0.48$ & 0.13 \\
\hline \multicolumn{4}{|l|}{ L-aniline } \\
\hline 0.05 & $-14.3 \pm 0.09$ & $12.4 \pm 0.30$ & 0.08 \\
\hline 0.1 & $-13.9 \pm 0.09$ & $14.2 \pm 0.47$ & 0.12 \\
\hline 0.2 & $-13.7 \pm 0.12$ & $10.5 \pm 0.42$ & 0.11 \\
\hline 0.3 & $-13.1 \pm 0.15$ & $14.2 \pm 0.51$ & 0.14 \\
\hline \multicolumn{4}{|l|}{ L-cysteine } \\
\hline 0.05 & $-14.2 \pm 0.14$ & $14.2 \pm 0.53$ & 0.13 \\
\hline 0.1 & $-13.2 \pm 0.05$ & $14.6 \pm 0.28$ & 0.15 \\
\hline 0.2 & $-13.0 \pm 0.04$ & $13.9 \pm 0.57$ & 0.14 \\
\hline 0.3 & $-12.6 \pm 0.13$ & $12.3 \pm 0.47$ & 0.13 \\
\hline \multicolumn{4}{|l|}{ L-histidine } \\
\hline 0.05 & $-14.1 \pm 0.06$ & $13.2 \pm 0.24$ & 0.06 \\
\hline 0.1 & $-13.0 \pm 0.12$ & $12.8 \pm 0.44$ & 0.11 \\
\hline 0.2 & $-12.4 \pm 0.10$ & $12.2 \pm 0.37$ & 0.10 \\
\hline \multicolumn{4}{|l|}{$\mathrm{NaCl}$} \\
\hline 0.05 & $-13.4 \pm 0.10$ & $10.6 \pm 0.30$ & 0.09 \\
\hline 0.1 & $-12.7 \pm 0.13$ & $8.6 \pm 0.40$ & 0.11 \\
\hline 0.2 & $-11.4 \pm 0.09$ & $8.4 \pm 0.30$ & 0.09 \\
\hline 0.3 & $-10.8 \pm 0.03$ & $6.8 \pm 0.14$ & 0.04 \\
\hline
\end{tabular}

${ }^{\mathrm{a}}$ Ref. [19]

of the solution compared with the pure solvent, as a result of strong solute and solvent interactions.

The apparent molar compressibilities were found to increase linearly with the molality of D-sorbitol. Thus, the apparent molar isentropic compressibilities at infinite dilution were obtained by using the method of linear regression of the following relation:

$$
\phi_{\mathrm{KS}}=\phi_{\mathrm{KS}}^{0}+S_{\mathrm{K}} m
$$

Table 16 presents the parameters of Eq. 9 together with the value of the limiting apparent molar compressibility of D-sorbitol in water obtained by Banipal et al. [19]. As is seen, the data from the present study is consistent with that from literature. To the best of my knowledge, no literature data on the compressibility data of D-sorbitol in aqueous amino acid or $\mathrm{NaCl}$ solutions is available for comparison purposes.

The values of the limiting apparent molar compressibilities of D-sorbitol increase (become less negative) with the increase in molality of co-solute. Obviously, this is the result of the fact that when sugar alcohol is dissolved in aqueous amino acid or salt solution, interactions between co-solute and water and between water molecules themselves are disrupted and interactions between solute and co-solute and between solute and water are formed. Thus, with increasing concentration of co-solute, more water molecules are released into the bulk solution and the solution becomes more compressible. 
Fig. 5 The limiting apparent molar compressibilities of transfer of D-sorbitol versus molalities of L-alanine (filled circles), L-cysteine (filled squares), L-histidine (filled inverted triangle) and $\mathrm{NaCl}$ (filled square) at $298.15 \mathrm{~K}$

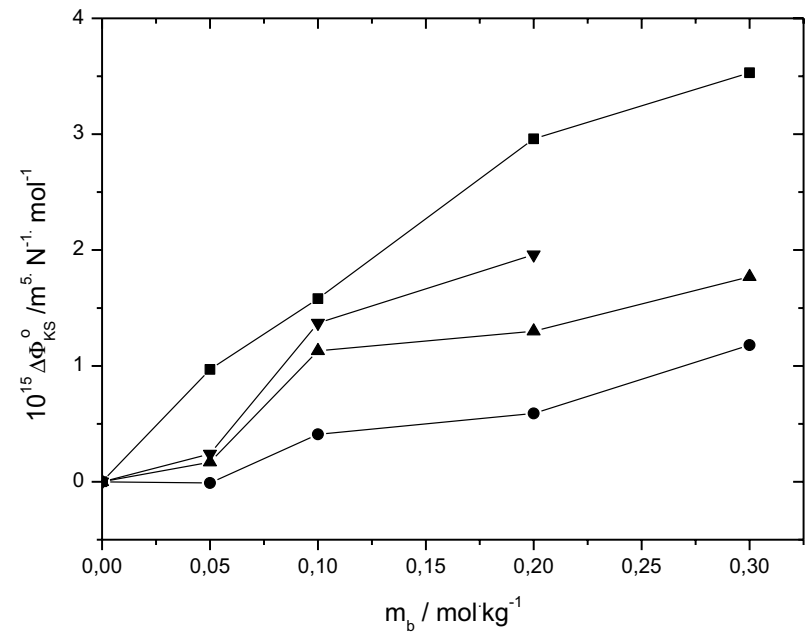

The obtained values of $\phi_{\mathrm{KS}}^{0}$ were used to calculate the limiting apparent molar compressibilities of transfer of D-sorbitol from aqueous to aqueous amino acid or sodium chloride solutions according to the equation:

$$
\Delta_{\mathrm{t}} \phi_{\mathrm{KS}}^{0}=\phi_{\mathrm{KS}}^{0}\left(\mathrm{H}_{2} \mathrm{O}+\text { co-solute }\right)-\phi_{\mathrm{KS}}^{0}\left(\mathrm{H}_{2} \mathrm{O}\right)
$$

Figure 5 presents the limiting apparent molar compressibilities of transfer of D-sorbitol versus molalities of L-alanine, L-cysteine, L- histidine and $\mathrm{NaCl}$. It can be seen that the $\Delta_{\mathrm{t}} \phi_{\mathrm{KS}}^{0}$ values are positive, they increase with the concentration of the co-solute and they may be arranged in the same ascending order as $\Delta_{\mathrm{t}} \phi_{\mathrm{V}}^{0}$ values, i.e. L-alanine $<$ L-cysteine $<$ L-histidine $<$ sodium chloride. The results obtained from acoustic studies are in accordance with the results from volumetric studies discussed earlier. They support the conclusion that the hydrophilic-ionic and hydrophilic-hydrophilic interactions in solutions of D-sorbitol in aqueous amino acids are predominant, while the properties of solutions of D-sorbitol in aqueous sodium chloride are determined by hydrophilic-ionic interactions. Moreover, the absence of hydrophobic-hydrophobic and hydrophilic-hydrophobic interactions in the ternary system (D-sorbitol $+\mathrm{NaCl}+$ water) results in more positive values of the limiting apparent molar properties of transfer.

\section{Conclusions}

The limiting apparent molar volumes and the limiting apparent molar compressibilities of transfer have been determined for the transfer of D-sorbitol from water to aqueous solutions of L-alanine, L-cysteine, L-histidine and $\mathrm{NaCl}$. Positive $\Delta_{\mathrm{t}} \phi_{\mathrm{V}}^{0}$ and $\Delta_{\mathrm{t}} \phi_{\mathrm{KS}}^{0}$ values have been obtained in all cases, and their magnitude increases with increasing concentration of cosolute, indicating the domination of hydrophilic-ionic interactions in solutions of D-sorbitol in aqueous sodium chloride and the co-domination of hydrophilic-ionic and hydrophilic-hydrophilic interactions in solutions of D-sorbitol in aqueous amino acids. As the obtained values of the limiting apparent molar expansibilities are positive and decrease as the temperature rises, these dominating effects also increase with rising temperature. 
The fact that the highest values of the limiting apparent molar volumes and the limiting apparent molar compressibilities were obtained for the (D-sorbitol $+\mathrm{NaCl}+$ water) ternary system indicates that interactions between solute and co-solute in this system are stronger than in (D-sorbitol + amino acid + water) mixtures. Moreover, the order of $\Delta_{\mathrm{t}} \phi_{\mathrm{V}}^{0}$ and $\Delta_{\mathrm{t}} \phi_{\mathrm{KS}}^{0}$ values obtained for D-sorbitol in aqueous solutions of L-alanine, L-cysteine and L-histidine, i.e. three amino acids with the same alkyl chain length, strongly suggests that the strength of alcohol sugar and amino acid interactions is determined by the hydrophobicity of amino acid.

The fact that the pairwise interaction coefficients are positive and of greater magnitude than the triplet interaction coefficients supports the conclusion that the properties of the studied solutions are determined by the strong interactions between D-sorbitol and amino acids or sodium chloride.

Acknowledgements I am indebted to Mrs. K. Fiałek for valuable technical assistance.

Open Access This article is distributed under the terms of the Creative Commons Attribution 4.0 International License (http://creativecommons.org/licenses/by/4.0/), which permits unrestricted use, distribution, and reproduction in any medium, provided you give appropriate credit to the original author(s) and the source, provide a link to the Creative Commons license, and indicate if changes were made.

\section{References}

1. Ortiz, M.E., Bleckwedel, J., Raya, R.R., Mozzi, F.: Biotechnological and in situ food production of polyols by lactic acid bacteria. Appl. Microbiol. Biotechnol. 97, 4713-4726 (2013)

2. Amaral, L.F.B., Camilo, N.S., Pereda, M.D.C.V., Levy, C.E., Moriel, P., Mozzola, P.G.: Evaluation of antimicrobial effectiveness of C-8 xylitol monoester as an alternative preservative for cosmetic products. Int. J. Cosm. Sci. 33, 391-397 (2011)

3. Grembecka, M.: Sugar alcohols - their role in the modern world of sweeteners: a review. Eur. Food Res. Technol. 242, 1-14 (2015)

4. Kumar, V., Chari, R., Sharma, V.K., Kalonia, D.S.: Modulation of the thermodynamic stability of proteins by polyols: significance of polyol hydrophobicity and impact on the chemical potential of water. Int. J. Pharm. 413, 19-28 (2011)

5. Pazhang, M., Mehrnejad, F., Pazhang, Y., Falahati, H., Chaparzadeh, N.: Effect of sorbitol and glycerol on the stability of trypsin and difference between their stabilization effects in the various solvents. Biotechnol. Appl. Biochem. 63, 206-213 (2016)

6. Mathew, A.P., Dufresne, A.: Plasticized waxy maize starch: effect of polyols and relative humidity on material properties. Biomacromolecules 3, 1101-1108 (2002)

7. Patriarca, A., Larumbe, G., Buera, M.P., Vaamonde, G.: Stimulating effect of sorbitol and xylitol on germination and growth of some xerophilic fungi. Food Microbiol. 28, 1463-1467 (2011)

8. Franks, F., Reid, D.S., Suggett, A.: Conformation and hydration of sugars and related compounds in dilute aqueous solution. J. Solution Chem. 2, 99-118 (1973)

9. Yasra, R.V., Ahluwalia, J.C.: Thermodynamics of transfer of sorbitol and mannitol from water to aqueous solutions of urea, guanidine hydrochloride and sodium chloride. J. Chem. Soc. Faraday Trans. I 78, 1677-1687 (1981)

10. Ali, A., Bidhuri, P.: Solvation thermodynamics of xylitol in water and in aqueous amino acids at 298.15 K. J. Phys. Org. Chem. 26, 54-58 (2013)

11. Ren, X., Zhu, C., Ma, Y.: Volumetric and viscometric studies of amino acids in mannitol aqueous solutions at $T=(293.15$ to 323.15) K. J. Chem. Eng. Data 60, 1787-1802 (2015)

12. Wang, X., Fu, R., Guo, Y., Lin, R.: Volumetric properties of amino acids in aqueous D-mannitol solutions at 298.15 K. J. Mol. Liq. 197, 73-76 (2014)

13. Liu, M., Wang, L., Li, G., Dong, L., Sun, D., Zhu, L., Di, Y.: Enthalpy of dilution and volumetric properties of N-glycylglycine in aqueous xylitol solutions at $T=298.15 \mathrm{~K}$. J. Chem. Thermodyn. 43, 983-988 (2011) 
14. Guo, L., Xu, L., Ma, L., Lin, R.: Transfer volumes of small peptides from water to aqueous xylitol solutions at 298.15 K. J. Solution Chem. 38, 383-389 (2009)

15. DiPaola, G., Belleau, B.: Apparent molal heat capacities and volumes of amino acids in aqueous polyol solutions. Can. J. Chem. 56, 1827-1831 (1978)

16. Jha, N.S., Kishore, N.: Thermodynamics of the interaction of a homologous series of amino acids with sorbitol. J. Solution Chem. 39, 1454-1473 (2010)

17. Ren, X., Zhu, C., Ma, Y.: Volumetric and viscometric study of amino acids in aqueous sorbitol solution at different temperatures. J. Chem. Thermodyn. 93, 179-192 (2016)

18. Banipal, P.K., Kaur, K., Banipal, T.S.: Modulation in physico-chemical characteristics of some polyhydroxy solutes in presence of L-glycine: volumetric and NMR spectroscopic approach. Fluid Phase Equilib. 402, 113-123 (2015)

19. Banipal, T.S., Sharma, S., Lark, B.S., Banipal, P.K.: Thermodynamic and transport properties of sorbitol and mannitol in water and in mixed aqueous solutions. Indian J. Chem. 38, 1106-1115 (1999)

20. Wurzburger, S., Sartorio, R., Guarino, G., Nisi, M.: Volumetric properties of aqueous solutions of polyols between 0.5 and $25^{\circ}$ C. J. Chem. Soc. Faraday Trans. I. 84, 2279-2287 (1988)

21. Jasra, R.V., Ahluwalia, J.C.: Thermodynamics of transfer of sorbitol and mannitol from water to aqueous solutions of urea, guanidine hydrochloride and sodium chloride. J. Chem. Soc. Faraday Trans. I. 78, 1677-1687 (1988)

22. Hepler, L.G.: Thermal expansion and structure in water and aqueous solutions. Can. J. Chem. 47, 4613-4617 (1969)

23. Shahidi, F., Farrell, P.G., Edward, J.T.: Partial molar volumes of organic compounds in water. III. Carbohydrates. J. Solution Chem. 5, 807-816 (1976)

24. Gurney, R.W.: Ionic Processes in Solution, vol. 3, pp. 1-20. McGraw Hill, New York (1953)

25. Kapcha, L.H., Rossky, P.J.: A Simple atomic-level hydrophobicity scale reveals protein interfacial structure. J. Mol. Biol. 426, 484-498 (2014)

26. McMillan Jr., W.G., Mayer, J.E.: The statistical thermodynamics of multicomponent systems. J. Chem. Phys. 13, 276-305 (1945)

27. Friedman, H.L., Krishnan, C.V.: Studies of hydrophobic bonding in aqueous alcohols: enthalpy measurements and model calculations. J. Solution Chem. 2, 119-140 (1973) 